Below is the unedited draft of the article that has been accepted for publication

(C) Consciousness and Cognition, 2020, V. 86, 103031; https://doi.org/10.1016/j.concog.2020.103031)

\title{
Selfhood triumvirate: from phenomenology to brain activity and back again
}

\author{
Andrew A. Fingelkurts ${ }^{\text {a, }}$, Alexander A. Fingelkurts ${ }^{\text {a }}$, Tarja Kallio-Tamminen ${ }^{\text {b }}$ \\ ${ }^{a}$ BM-Science-Brain and Mind Technologies Research Centre, Espoo, Finland \\ ${ }^{\mathrm{b}}$ Physics Foundations Society and Society for Natural \\ Philosophy, Helsinki, Finland
}

\begin{abstract}
:
Recently, a three-dimensional construct model for complex experiential Selfhood has been proposed (Fingelkurts et al., 2016b,c). According to this model, three specific subnets (or modules) of the brain selfreferential network (SRN) are responsible for the manifestation of three aspects/features of the subjective sense of Selfhood. Follow up multiple studies established a tight relation between alterations in the functional integrity of the triad of SRN modules and related to them three aspects/features of the sense of self; however, the causality of this relation is yet to be shown. In this article we approached the question of causality by exploring functional integrity within the three SRN modules that are thought to underlie the three phenomenal components of Selfhood while these components were manipulated mentally by experienced meditators in a controlled and independent manner. Participants were requested, in a blockrandomised manner, to mentally induce states representing either increased (up-regulation) or decreased (down-regulation) sense of (a) witnessing agency (“Self”), or (b) body representational-emotional agency ("Me"), or (c) reflective/narrative agency ("I"), while their brain activity was recorded by an electroencephalogram (EEG). This EEG-data was complemented by first-person phenomenological reports and standardised questionnaires which focused on subjective contents of three aspects of Selfhood. The results of the study strengthen the case for a direct causative relationship between three phenomenological aspects of Selfhood and related to them three modules of the brain SRN. Furthermore, the putative integrative model of the dynamic interrelations among three modules of the SRN has been proposed.
\end{abstract}

\section{Keywords:}

Self-referential brain network; SRN; default-mode network; DMN; subjective sense of Self; first-person perspective; electroencephalogram; EEG; alpha rhythm; operational synchrony; functional connectivity; agency; ownership; mineness; embodiment; first-person perspective; narration; autobiography; selfconsciousness. 
[T] he self is the fundamental unit of analysis for a science of mental life, the problem about which everything else revolves.

(James, 1890; p. 221)

I know all these things, and what is more, I know that I know them. But who is it who has this perspectival grasp?... It is much easier to feel the self than to define the self.

(Allport, 1961; p. 128)

\section{Introduction}

We are living in a time of the greatest scientific endeavor - the attempt to understand the most difficult phenomenon of all times - the Self. Even though for centuries the study of self has been traditionally consigned to philosophy and religion, today, science and philosophy are converging in their exploration of the nature and mystery of Selfhood to make sense of who we are. While the self is a multilayered concept, and various disciplines tend to conceptualize it in different ways (Strawson, 1999; Zahavi \& Roepstorff, 2011; Gallagher, 2013; Musholt, 2015; Blackmore, 2015), the currently emerging consensus is that selfreferential processing constitutes the core of the "experiential self" which is the common "currency" of distinct concepts of self in different knowledge domains (Northoff et al., 2006; Northoff, 2016; but see Legrand \& Ruby, 2009 for some critique). The convergent empirical evidence from neuroscience (Raichle et al., 2001; Gusnard, 2005; Northoff et al., 2006, 2011; Schilbach et al., 2008; Fingelkurts \& Fingelkurts, 2011), combined with studies of direct relationship between brain activity and the self (Lou et al., 2004, 2010; Tsakiris et al. 2008; Luber et al., 2012; Chen et al., 2013), suggests that in the brain such selfreferential processing is instantiated by the specific self-referential network (SRN), sometimes also referred to as the default mode network (Raichle et al., 2001; Gusnard, 2005; Schilbach et al., 2008; Fingelkurts et al., 2012).

Another piece of important evidence comes from ontogenesis studies where anatomic development of the SRN and self-referential processing shares the same developmental trajectory. Indeed, structurally the SRN does not exist in preterm infants (Fransson et al., 2007, 2009), is underdeveloped in term infants (Gao et al., 2009), and only reaches an adult-like structural pattern around the age of 7-9 years (Fair et al., 2008; Thomason et al. 2008). These neuroanatomical observations are paralleled by data obtained within developmental psychology (Gopnik \& Slaughter, 1991; Povinelli et al., 1996; Asendorf, 2002; Butterworth, 2000; Tomasello \& Rakoczy, 2003), that show that awareness of "points of view" and thus "perspective taking", first begins to develop when a child is about 2 years old, and it is almost fully developed by the time the child becomes a fluent language user, around the age of 4-5 years. Before that, there is no stable 
awareness of "points of views" being different for different persons (the infants take their own visual field to be held in common with others; Butterworth, 2000), nor therefore, as claimed by Praetorius (2009), any awareness of the subjectivity of one's own experiences, i.e. no awareness that one's experiences uniquely belong to oneself as "mine" as opposed to those of others (see also the review and discussion of these studies by Welsh, 2006).

The SRN's role in supporting self-conscious experience is further confirmed by empirical evidence coming from patients with disorders of consciousness (Laureys 2005; Vanhaudenhuyse et al., 2010; Fingelkurts et al., 2012, 2016a), as well as studies of anesthesia (Greicius et al., 2008) and brain death (Boly et al., 2009).

Capitalizing on these findings and considering current advances in understanding the complex role of the SRN (Kim, 2012; Molnar-Szakacs \& Uddin, 2013; Andrews-Hanna et al., 2014; Fox et al., 2015; Davey et al., 2016), as well as empirical evidence on the functional and topographical specialization of three main subnets (or operational modules) of SRN during normal/healthy states (Uddin et al., 2009; Andrews-Hanna et al., 2010; Fingelkurts \& Fingelkurts, 2011; Sestieri et al., 2011) and pathological conditions where selfconsciousness is either minimal or lost completely (Laureys, 2005; Greicius et al., 2008; Vanhaudenhuyse et al., 2010; Boly et al., 2009; Fingelkurts et al., 2012, 2016a), a three-dimensional construct model for complex experiential Selfhood has been proposed recently (Fingelkurts et al., 2016b,c). This model "potentially allows the operationalization of key features of the self" (Vogeley \& Gallagher, 2011; p. 112) in a way that is most suitable for neuroscientific investigation without neglecting phenomenological insights (Varela, 1996; Gallagher \& Zahavi, 2012), thus helping to bridge gap between neuroscientific and philosophical approaches to the study of self (Chiong, 2011). According to Northoff (2014a), such a "neurophenomenal approach", which specifies the relationship between specific neuronal processes operating in the brain and specific phenomenal features in the subjective experience, establishes the foundations for a "nonreductive neurophilosophy" (Northoff, 2014b, 2016).

\subsection{The triad model of the complex experiential Selfhood}

The triad model of Selfhood (Fingelkurts et al., 2016b,c) is rooted in evidence that the SRN is a highly heterogeneous brain network composed of at least three major spatially separate yet functionally interacting subnets (or operational modules - OMs), each consisting of a set of brain regions having tight "functional connectivity" within every given OM (Fingelkurts \& Fingelkurts, 2011; see also Uddin et al., 2009; Andrews-Hanna et al., 2010; Spreng \& Grady, 2010; Leech et al., 2011). These three OMs include the anterior OM and two symmetrical (left and right) occipito-parieto-temporal OMs (Fig. 1) which can be reliably estimated (Fingelkurts \& Fingelkurts, 2011, 2012, 2017a,b; Fingelkurts et al., 2016a,b,c) through operational synchrony analysis of the electroencephalogram (EEG) signal (Fingelkurts \& Fingelkurts, 2008, 2015a). The triad model considers and is congruent with the multi-faceted nature of self-awareness (Snodgrass \& Thompson, 1997; Klein \& Gangi, 2010; Musholt, 2013) where three major components of 
Selfhood (phenomenal first-person agency, embodiment, and reflection/narration) can be phenomenologically distinguished (Gallagher, 2000; Zahavi, 2002; Hohwy, 2007). Thus, this triad model offers a useful and practical "tool" that enables neurophysiological study of three separate, though closely related qualities characterizing self-referential processing that together form a unified sense of self (Fingelkurts \& Fingelkurts, 2011).

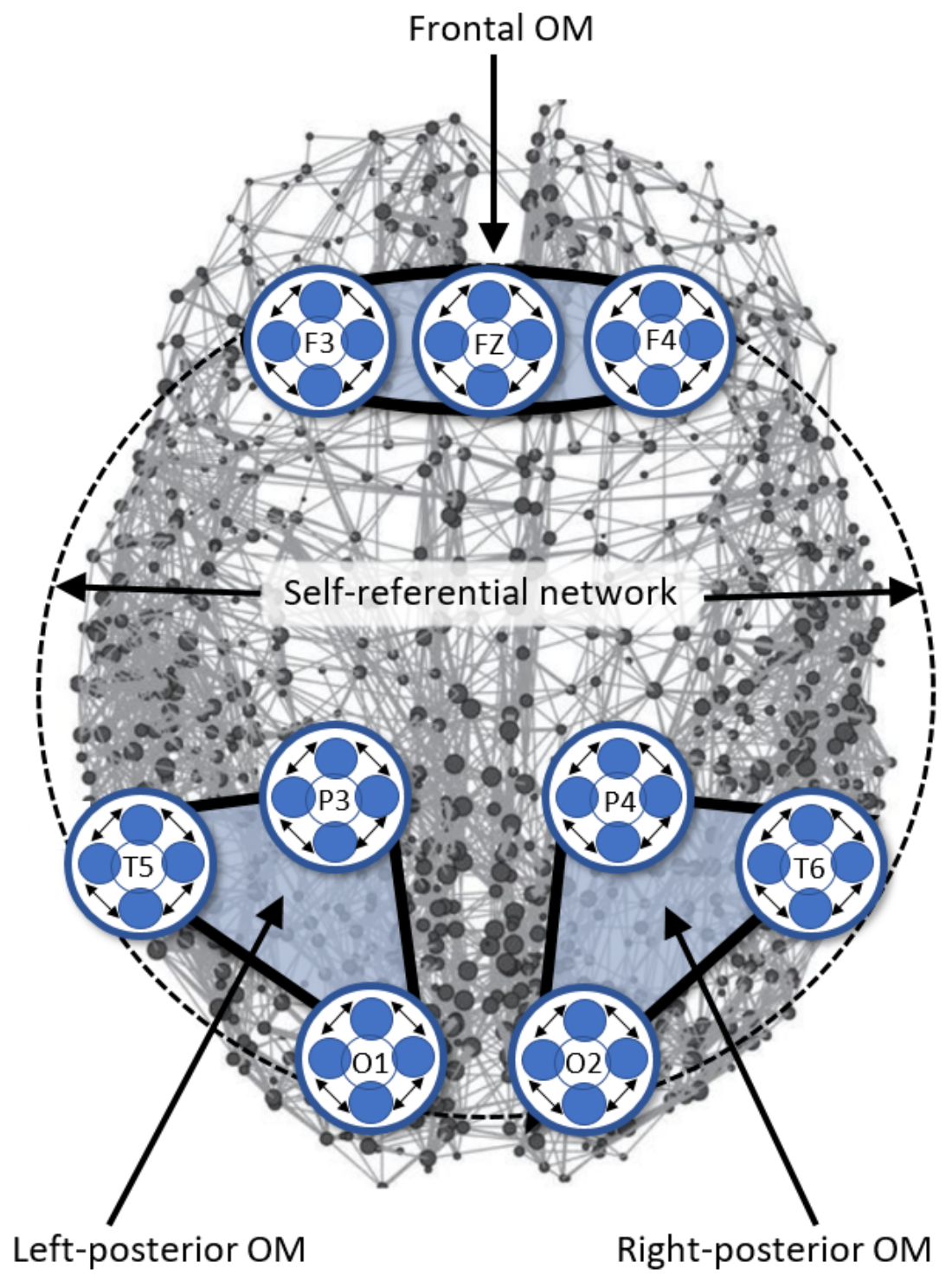

Figure 1. Operational modules (subnets) of the self-referential brain network. Statistically significant ( $p$ $<0.05$ ) values of operational synchrony among EEG locations (marked by white circles with EEG electrode IDs) that are involved in every OM are mapped onto a schematic cortex map as blue coloured areas indicating OMs. A schematic cortex map presents the brain's functional connections with dark grey spheres marking network nodes and light grey lines representing their functional connections. The network nodes are shown in their respective anatomical coordinates, hence preserving the spatial embedding of the network. Every OM has a clear nested functional hierarchy. In a nested hierarchy, higher levels are physically composed of lower levels (Feinberg, 2012). Indeed, every OM is a functional integration of several local brain fields (registered by the correspondent EEG electrodes), which in their turn are the integration of yet smaller local fields of transient functional neuronal assemblies (Fingelkurts \& Fingelkurts, 2001, 2013; Fingelkurts et al., 2019; see also Freeman \& Kozma, 2000; Kozma \& Freeman, 2009; Freeman et al., 2015). All three OMs, together, form a higher level of a functional nested architecture - the self-referential network 
(marked as a dashed circle line that connects three OMs). Abbreviations: EEG: electroencephalogram; OM: operational module; Double-pointed arrows schematically indicate functional couplings of the local fields produced by neuronal assemblies under a given electrode; Electrode positions: F3 - left frontal, $\mathrm{Fz}$ - frontal midline, F4 - right frontal, T5 - left temporal, P3 - left parietal, O1 - left occipital, T6 - right temporal, P4 right parietal, $\mathrm{O} 2$ - right occipital.

Such an approach is compatible with Gallagher's "pattern theory of self" (2013), where self is a complex pattern emerging from dynamic interactions of characteristic aspects/features/qualities/components that jointly constitute self, although no individual feature by itself may be necessary or specific to constitute a self (Legrand \& Ruby, 2009). In this view, "we should not think of such aspects as aspects of "the self," as if they are simply modifying something that has its own independent existence" (Gallagher, 2013; p. 1); instead self should be viewed as a complex pattern that emerge from dynamic interactions of constituent aspects or features (Gallagher, 2013). The triad model of Selfhood extends the pattern theory of self further by introducing hierarchical nestedness into the dynamic pattern (Fingelkurts \& Fingelkurts, 2012). Nestedness comes from the fact that a certain pattern of low-level features forms a particular higher-level feature/quality/component of self, whereas the dynamic interaction of such higher-level characteristic features/qualities constitutes even higher level of hierarchy - an individual self. Since the characteristic features/qualities/components can take different weights and interact with different strength at every level of the nested hierarchy, the expression of self should vary within the individual over time, and also from one individual to another (Gallagher \& Daly, 2018). Neurophysiologically, nestedness is in-built in the triad model of selfhood (Fig. 1): every OM is a set of local brain fields generated by distant transient neuronal assemblies (located in different brain areas) having tight "functional coupling" within every OM (Fingelkurts \& Fingelkurts, 2011, 2013) and together these three OMs form a higher-level dynamic complex functional structure - the SRN (Fingelkurts \& Fingelkurts, 2011).

According to the triad model of selfhood (Fingelkurts et al., 2016b,c), the frontal module of the SRN (Fig. 1) is linked with the phenomenal first-person perspective and the sense of agency. We label it the "witnessing observer" or simply the "Self" in the narrowest sense - the phenomenal non-conceptual core in the act of knowing itself $^{1}$ (Blanke \& Metzinger, 2009; Velmans, 2014). The brain structures contributing to this module have been documented to be directly involved in the sense of being a self (ie, being a subject/agent of self-conscious experience; Northoff \& Bermpohl, 2004; Kwan et al., 2007; Andrews-Hanna, 2012; Moran et al., 2013; Musholt, 2013), where one feels directly and immediately present as the center of a phenomenal multimodal perceptual reality (the focus of one's phenomenal experience or a sensed "centre of

\footnotetext{
${ }^{1}$ To avoid any misunderstanding, this "witnessing observer" should not be confused with the other notion of "witnessconsciousness" which refers to a long-standing concept (sākșin) in classical Advaita Vedanta philosophy (Chatterjee, 1982; Fort, 1984; Gupta, 1998; Fasching, 2010). "Witness-consciousness" while being the basis of all knowing, it can never become an object of knowledge by itself (Gupta, 1998; Josipovic, 2014). Thus, it strongly resembles what one would experience if "witnessing observer" would disappear - a wakeful but contentless (nonintentional) consciousness (Forman, 1998) not tied to a phenomenal first-person perspective (Metzinger, 2020). Hence, it is the opposite "end" (counterpart) of the "witnessing observer".
} 
gravity"; Velmans, 2014), thus having the phenomenal first-person perspective (Metzinger, 2004, 2008; Revonsuo, 2006; Trehub, 2007; Blanke \& Metzinger, 2009). Here agency is understood as the "sense of ownership" of thoughts, perceptions, and actions relevant to Selfhood (Metzinger, 2004, 2008; de Vignemont \& Fourneret, 2004; Hohwy, 2007; Blanke \& Metzinger, 2009). Broadly speaking, agency means the sense that it is "I" who is undergoing an experience in its implicit first-person mode of givenness (Gallagher, 2000; Zahavi, 2002; Metzinger, 2008). Following this conceptualization, the agent could be a passive observer, who just witnesses events, perceptions, or thoughts in its implicit first-person mode of givenness (Fingelkurts et al., 2016b). The experiential feeling of being a "witnessing observer" (self in the act of knowing) can be voluntary manipulated (enhanced and sharpened), for example, as a function of meditation training (Fingelkurts et al., 2016b,c; Lutz et al., 2008; Kerr et al., 2011), or arise in pathologic circumstances like depression (Fingelkurts \& Fingelkurts, 2017a), and post-traumatic stress disorder (Fingelkurts \& Fingelkurts, 2018). It can also diminish or disappear, as for example, in patients with disorders of consciousness (Fingelkurts et al., 2012, 2016a; Fingelkurts \& Fingelkurts, 2017b, Huang et al., 2014), during dreamless sleep (Thompson, 2015; Windt, 2015), in specific meditative states (Wahbeh et al., 2018; Josipovic, 2019) or under psychedelics like 5-MeO-DMT (Millière, 2017, 2020; Deane, 2020; Letheby, 2020).

The right posterior module of the SRN (Fig. 1) is associated with the experience of self as a normally localized within bodily boundaries (through interoceptive and exteroceptive sensory processing) entity, emotional states, and related autobiographical emotional memories (Fingelkurts et al., 2016b,c). We label this module "representational-emotional agency" or simply "Me", while others call it "proto-self" (Panksepp, 2005; Panksepp \& Northoff, 2009) or “minimal self” (Gallagher, 2000; Gallagher \& Frith, 2003). In contrast to a phenomenal first-person perspective, here only a purely geometrical first-person perspective is present that originates within the body representation, thus signifying an egocentric spatiotemporal self-model (Blanke \& Metzinger, 2009). This understanding is consistent with enactivist notion of system autonomy (see Bitbol \& Gallagher, 2018; Gallagher \& Allen, 2018; Bruineberg et al., 2018): “An autonomous system produces and sustains its own identity $[\ldots]$ and thereby establishes a perspective from which interactions with the world acquire a normative status" (Thompson \& Stapleton, 2009; p. 25). The body here is not just one more object of the physical world, but a "vehicle" that enables being a self in the world (Varela et al., 1994; Gallagher, 2005; Legrand, 2006; Hohwy, 2010, 2013; Seth et al., 2012; Limanowski \& Blankenburg, 2013; Apps \& Tsakiris, 2014). The brain areas contributing to this module have been shown to be consistently involved in the embodied aspects of self-related experiences and associated emotional states (Berlucchi \& Aglioti, 1997; Damasio, 1999; Downing et al., 2001; Farrer et al., 2003; Astafiev et al., 2004; Critchley et al., 2004; Panksepp, 2005; Ionta et al., 2011; Blanke, 2012; Múnera et al., 2014; Park \&TallonBaudry, 2014). Such a sense of bodily self (or "Me") can be altered or become abnormal during various pathological conditions, as for example in vegetative or minimally conscious states (Fingelkurts et al., 2012), depression (Fingelkurts \& Fingelkurts, 2017a), post-traumatic stress disorder (Fingelkurts \& Fingelkurts, 2018), heautoscopic out-of-body experiences (Blanke \& Mohr, 2005; Blanke et al., 2002; Ionta et al., 2011), or in depersonalization syndrome where the sense of body ownership is lost (Berlucchi \& Aglioti, 1997). It 
can also be intentionally manipulated, as for example, through a long-term meditation training, where experiencing "self-boundarylessness" or loss of bodily perceptions is effectively achieved (Newberg et al., 2001; Newberg \& Iversen, 2003; Berkovich-Ohana et al., 2013; Ataria et al., 2015; Fingelkurts et al., 2016c).

The left posterior module of the SRN (Fig. 1) is involved in experience of thinking about and reflecting upon oneself, including momentary narrative thoughts and inner speech, as well as reinterpretation of episodic and semantic memory events related to self - autobiographical story telling (Fingelkurts et al., 2016 b,c). We label it "reflective agency" or simply "I", while in the literature other terms have been used like the "narrative self" (Gallagher, 2000), "conceptual self" (Neisser, 1988; Demiray \& Bluck, 2011), "autonoetic self" (Gardiner, 2001; Klein, 2016) or "autobiographical self" (Damasio, 1999, 2010). As Gallagher and Zahavi (2015) correctly pointed out, reflective self-consciousness presupposes the existence of both conceptual knowledge and narrative competence. It also requires a certain level of maturation and the ability to access and self-report about states, traits, and dispositions that make the person exactly who she/he is. Further, cultural and social influences can contribute to shaping and maintaining internal models through personal narrative representations (Shotter, 1997; Hirsh et al., 2013; Gallagher \& Daly, 2018), that serve as a link between private psychological states and the social world (Kirmayer \& Crafa, 2014; Frith \& Metzinger, 2016). It has been suggested that the self-reflected form of conceptual self relies on uniquely human capabilities for language and self-reflection (Damasio, 1994; Budwig, 2000; Gallagher, 2000; Craig, 2004) and provides the basis for explaining the often-discussed invariance of Selfhood over time (James, 1890; Metzinger, 2003; Friston et al., 2017). The described aspects of self-reflection have been related to the activity of brain structures involved in the left posterior module of the SRN (Mar, 2004; D'Argembeau et al., 2005; Moriguchi et al., 2006; Brownsett \& Wise, 2010; Longe et al., 2010; Friston, 2011; Perlovsky, 2011; Tops et al., 2014). The activity of this module and related subjective experiences can be altered in different pathologies, like schizophrenia, depression, post-traumatic stress disorder or brain injury (Frith, 1992; Gallagher, 2003a; Moseley et al., 2013; Fingelkurts \& Fingelkurts, 2017a,b, 2018); it also can be voluntary modified through a specialized self-training, such as for example, meditation (Fingelkurts et al., 2016c).

Together, the described triad of the SRN OMs provides a coherent instantiation of complex Selfhood (Fingelkurts \& Fingelkurts, 2011; Fingelkurts et al., 2016b,c). As clarified above, the proposed triad of aspects of self (witnessing observer, representational-emotional agency, and reflective agency) cannot be reduced into one another; however, they are nonetheless intertwined and all three are intrinsic dimensions that together constitute a unique phenomenal pattern - a Self.

\subsection{Application of the triad model of Selfhood to different pathologies}

Current empirical evidence from psychiatric and neurological conditions suggest a clear correlation between the internal integrity (functional connectivity) within every of the three SRN OMs and related to them triad aspects/qualities of Selfhood. They also reveal the nature of the dynamical relations among the three qualities of self, helping to understand how they could be integrated or disintegrated in particular cases 
of pathology. For example, application of the triad model of Selfhood to unmedicated major depressive disorder (Fingelkurts \& Fingelkurts, 2017a) revealed that depression is associated with hypersynchrony in all three OMs (the "Self" OM having the strongest synchrony increase and the "Me" OM - the weakest increase among all three OMs), thus reflecting the well-documented excessive self-focus, rumination, and embodiment in patients with depression (Beck, 1987; Damasio, 1999; Rimes \& Watkins, 2005; Northoff, 2007; Nolen-Hoeksema, 2008; Paulus \& Stein, 2010). It has been proposed that "these three components of complex Selfhood (indexed by distinct OMs of the self-referential brain network) synergize one another in a maladaptive loop and overtime become habitual, leading to a vicious circle that maintains a disordered affective state that clinically manifests as depression" (Fingelkurts \& Fingelkurts, 2017a; p. 34). One could further speculate that in such a constellation of SRN OMs, the "Self" OM has a special role as it organises, represents and appraises the salience of interoceptive/emotional/bodily information presented by the "Me" $\mathrm{OM}$ and the narrative and semantic-conceptual information presented by the "I" OM (Fingelkurts \& Fingelkurts, 2017a).

A different pattern of Self-Me-I dynamics was revealed in post-traumatic stress disorder (PTSD). Applying the triad model of Selfhood to PTSD, it has been found (Fingelkurts \& Fingelkurts, 2018) that increased functional connectivity of the "Self" OM was significantly associated with increased vigilance of PTSD sufferers to their surroundings with a concurrent shift of their first-person perspective from the current moment in time to the moment of the traumatic event (criterion E according to DSM-5; Diagnostic and Statistical Manual of Mental Disorders, 2013). One may propose that constant hypervigilance coupled with profound emotional arousal would lead to a sensory overload and further exacerbate alienation of the self in such patients (Zepinic, 2011). Additionally, increased synchrony of the "Me" OM was significantly linked to enhanced emotional, sensory and bodily states in PTSD sufferers (criterion D according to DSM-5), such as fear, stress, frozenness, shivering, shaking, trembling, palpitations and sweating (van der Kolk, 1994; McNally, 2003; Ataria, 2014). Such feelings are usually reported as intrusive and unwanted memories (criterion B according to DSM-5). Furthermore, decreased functional connectivity of the "I" OM was significantly associated with lack of linguistic/contextual information and narrative (criterion $\mathrm{C}$ according to DSM-5) as documented in PTSD patients (van der Kolk \& Fisler, 1995; Ataria, 2014).

Further, a six-year longitudinal analysis of a single patient's recovery of self-consciousness (from the minimally conscious state till full self-consciousness and nearly complete functional independence) after the extremely severe traumatic brain injury has confirmed that functional integrity of the three SRN OMs is indeed coupled with corresponding aspects of complex selfhood, such as first-person agency (or "Self"), representational-emotional agency (or "Me"), and reflective agency (or "I") (Fingelkurts \& Fingelkurts, 2017b). Such dynamics in the Self-Me-I components (and corresponding OMs) were not monotonous, they were unique for every component/OM (some responded quickly while others lagged behind), and were tightly paralleled by (and significantly correlated with) findings from clinical exams and tests (Fingelkurts \& Fingelkurts, 2017b; Kullberg-Turtiainen et al., 2019). 
While these findings on the tight relation between alterations in the triad of SRN OMs and related three aspects/features of the sense of self have obvious theoretical, scientific and clinical implications, causality of this relation has not yet been established. One way of approaching the causality is to explore the functional integrity within the three SRN OMs that underlie the three components of the sense of Selfhood while these very components are manipulated mentally by the experienced meditators in a controlled and independent manner. We reasoned that if the neurophenomenological triad model of Selfhood is correct, and meditators manage to achieve in a controlled manner the target mental states (either up-regulate or down-regulate every aspect of the triad qualities of self independently), then distinct and predictive changes in the functional integrity of every OM of the SRN should accompany the correspondent mental activation and deactivation. In other words, our hypothesis is that the up-regulated subjective sense of a particular component of self should result in increased OM integrity and a down-regulated subjective sense should cause a decrease in OM integrity in accordance with the neurophenomenological triad model of Selfhood.

\subsection{Aim of the study}

Therefore, the aim of this study was to explore the dynamics of functional integrity of the three SRN OMs (that relate to three components of the sense of Selfhood) while the experienced, advanced meditators mentally manipulate every component of self triad independently in a randomised, independent, and controlled manner.

For the purpose of this study we used advanced functional connectivity analysis within the three SRN OMs (measured by EEG operational synchrony) in highly experienced meditators, who through a long-term practice have learned to regulate and achieve various mental states in a reproducible manner (Depraz et al., 2003). During meditation period the participants were requested to mentally induce states representing either increased (up-regulation) or decreased (down-regulation) sense of (a) witnessing agency ("Self"), (b) body representational-emotional agency ("Me"), and (c) reflective/narrative agency ("I"), while their brain activity was monitored by EEG. This EEG-data was complemented by first-person phenomenological reports and standardised questionnaires (focusing on subjective contents of three aspects of Selfhood) to explore possible dimensions of inner experience of self and to ensure that specific target mental states were indeed being achieved, as instructed and intended. Furthermore, this approach was also expected to help us better characterise and increase our understanding of the characteristic components/features of Selfhood.

\section{Materials and methods}

\subsection{Subjects}


Eight ( 4 males / 4 females; mean age $=54.5, \mathrm{SD}=14.8$ ) long-term meditators with an average of 24 $(\mathrm{SD}=8.8)$ cumulative years of meditation practice, and an average of $4400(\mathrm{SD}=2300)$ total hours of meditation practice voluntary participated in the present study. All participants were right-handed with no history of neurological or mental disease, and had more than 15 years of education. Experienced meditators were chosen instead of ordinary persons because long-term contemplative practitioners were repeatedly documented as being able to voluntarily manipulate their subjective experiences within laboratory settings, to robustly reproduce specific features of an experience, to keep their attention for an extended temporal period on an target object of choice (breath, physical object or a produced state of self), and provide detailed first-person descriptions of their experiences (Lutz et al., 2007; Fox et al., 2012; Berkovich-Ohana et al. 2013; Dor-Ziderman et al. 2013; Ataria et al., 2015). The particular mediation technique used by these participants was not important, because participants were instructed to voluntary reach particular pre-defined mental states (see section Task below) instead of practicing a specific meditation.

Exclusion criteria included any history of neurologic and/or psychiatric disorder, brain trauma/concussion, epilepsy, serious somatic disorder in the past year, stressful events (e.g. job loss, divorce, bereavement, etc.) in the past 6 months, pregnancy (for the females), or usage a medication that may affect brain activity.

This study was carried out in accordance with the Code of Ethics of the World Medical Association (Declaration of Helsinki) and standards established by the BM-Science - Brain and Mind Technologies Research Centre Review Board. Prior to participating in the study and EEG scanning, the experimental procedures were explained and participants signed an informed consent form. The use of the data for scientific studies was authorized by written informed consent of subjects and approval by the Review Board of BM-Science - Brain and Mind Technologies Research Centre.

\subsection{Task}

Well in advance of the experiment, participants were introduced to the standard instructions aiming to either increase (up-regulate) or decrease (down-regulate) the sense of three targeted mental states: (a) witnessing agency ("Self”), or (b) body representational-emotional agency ("Me"), or (c) reflective/narrative agency ("I"). In doing so and in accordance with the recommendations of Gallagher and Sørensen (2006), participants were asked to suspend their own beliefs, metaphysical interpretations and theoretical background assumptions about the mental states they were going to achieve. Standard verbal guiding instructions were as follows. For "Me"-up state: "focus on a sense of the body, on the image of your body, on any tiny sensation your body feels, on the related emotional feelings; sense your position, posture or micromovement; sense yourself centered in this body from which you are experiencing the world". For "Me"-down state: "focus on a sense of open space without the bodily dimension; concentrate on the absence of the body physical image; try to experience yourself wider, expanded, less physically bounded, bodiless as in out-of-body experience". For "I"-up state: "focus on reflecting upon yourself; analyse yourself by silently talking to yourself; facilitate 
the labelling of every self-experience or self-memory you have". For "I"-down state: "try to accept without judgment all experiences and to refrain from applying evaluative labels such as good/bad, right/wrong, or worthwhile/worthless, and to allow self-reality to be as it is without attempts to avoid, escape, or change it; to slow the train of thoughts". For "Self"-up state: "focus on a nonsymbolic, non-linguistic sense of selfpresenting being; try to enhance the ability to merge into the self, which is a pure self-referential consciousness, where self is only aware of self". For "Self"-down state: "try to achieve a feeling like in a contentless dream, though being awake, where one experiences a subjective loss of access to the conscious world as well as of the first-person perspective".

Participants practiced each target state at home before the experiment to confirm that they understood and could follow the instructions. During the experiment, each EEG session-run began with a 5-min restingstate baseline period with eyes closed, which agrees with standard resting-state induction procedures (Brewer et al., 2011). This resting-state was followed by a 10-min target state period with eyes closed ${ }^{2}$. Every participant performed every target state with the same direction (up-regulation or down-regulation) three times. The timeline of the session is presented in the Figure 2. Every target state was assigned to participants

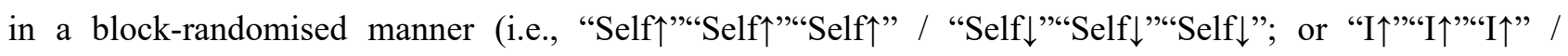

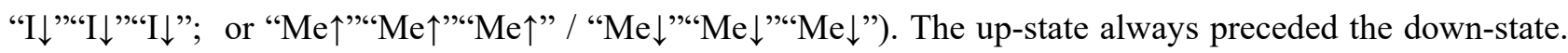
Since every session containing up- and down-regulated states took around three hours to complete, every participant was restricted to one session per day in order to avoid fatigue. By the time the study concluded, every participant had 3 days of EEG recordings. This resulted in total of 24 days and 64 hours of EEG recordings.

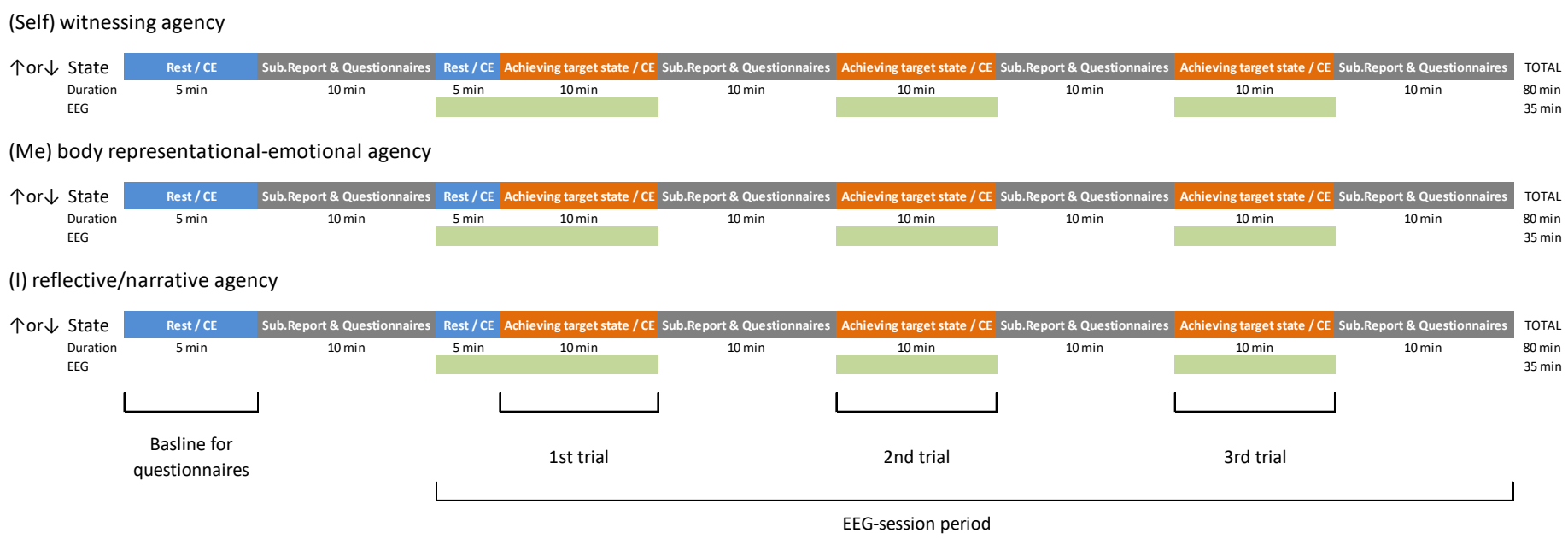

Figure 2. Schematic illustration of the study timeline. EEG: electroencephalogram recording; CE: closed eyes; $\uparrow:$ up-regulation of the corresponding state; $\downarrow$ : down-regulation of the corresponding state.

\footnotetext{
${ }^{2}$ Participants kept their eyes closed during the rest condition and also during the experimental task; no stimuli were presented, and no motor responses were required. Participants' activity during the contemplative tasks was exclusively internal, - in this respect, the mental conditions and rest were closely matched to each other.
} 


\subsection{Self-reports and questionnaires}

The current study used a neurophenomenological design (Gallagher, 2003b; Lutz \& Thompson, 2003; Fazelpour \& Thompson, 2015), incorporating both EEG recordings and first-person descriptions of the same subjects, as well as their replies to a set of standardised questionnaires. The first rest condition with eyes closed and without executing any task served as the baseline for participants to produce their subjective reports and answer questionnaires in relation to a baseline condition (Fig. 2). The following reports and questionnaire replies were collected immediately after every period of EEG recording while achieving a particular target mental state (see Fig. 2) in order to be sufficiently trustworthy (Windt, 2013) and minimize reliance on episodic recall inference, misremembering or confabulation (Jack \& Roepstorff, 2002; Windt 2013). In the Introspective Self-Report, participants were asked to describe in their own words their subjective state during achieving a target mental state, focusing on the internal process and specific aspects of the body awareness and sensations, vigilance, internal speech and narration, and the sense of witnessing. No constraints were specified on the type of reporting; any comments were welcomed. Additionally, participants were instructed to provide a Retrospective Self-Report by rating how well they were able to follow the instructions and reach the target state on a scale of 0 to 10 , with 0 signifying "no success at all" and 10 indicating a "complete success". This measure was used to allow post-hoc identification and exclusion of "unsuccessful" trials (rating equal or less than 5) from the further analysis. Self-reports were used because it is widely recognized that self-rating/reporting is more reliable than external ratings in assessment of subjective states (Sikka et al., 2014).

Additionally, participants filled in a set of standardised questionnaires (Fig. 2) using Likert-scale type of responses (Norman, 2010). The questionnaires were: (1) Sense of Agency Rating Scale - SOARS (Polito et al., 2013); with "Involuntariness" and "Effortlessness" factors used. (2) Rumination-Reflection Questionnaire - RRQ (Trapnell \& Campbell, 1999); with "Rumination" and "Reflection" factors used. (3) Five Facet Mindfulness Questionnaire - FFMQ (Baer et al., 2006); with "Observing” factor used. (4) Embodiment Questionnaire - EQ (Aymerich-Franch et al., 2015); with "Ownership", "Self-Location" and "Agency" factors used. (5) The Sense of Body - SB (an in-house questionnaire, following Pope \& Singer, 1978; Winget, \& Kramer, 1979); with "Body Image", "Body Perception" and "Body Orientation" factors used. (6) The Sense of Time (ST) and Thought Speed (TS) (another in-house questionnaire, following Pope \& Singer, 1978; Winget, \& Kramer, 1979); with "Here and Now", "Future", "Past", "Concatenation of Thoughts", "Continuity of Thoughts" and "Speed of Thoughts" factors used. (7) Self-Concept Clarity ScaleSCCS (Campbell et al., 1996). (8) Beck Anxiety Inventory - BAI (Beck et al., 1988). (9) Beck Depression Inventory - BDI (Beck et al., 1961). 


\subsection{EEG registration and pre-processing}

An EEG-signal was recorded during waking state ("rest" or "achieving a target state") with eyes closed using a 21-channel EEG data acquisition system (Mitsar, St. Petersburg, Russian Federation) from 19 electrodes positioned on the head according to the International 10-20 system (i.e. O1, O2, P3, P4, Pz, C3, C4, Cz, T3, T4, T5, T6, Fz, F3, F4, F7, F8, Fp1, Fp2). The timing of EEG recordings is illustrated in Figure 2. The following recording parameters were enforced: linked earlobes as a reference electrode; $0.5-30 \mathrm{~Hz}$ bandpass; $50 \mathrm{~Hz}$ notch filter $\mathrm{ON} ; 250 \mathrm{~Hz}$ sampling rate; electrooculogram $(0.5-70 \mathrm{~Hz}$ bandpass); with impedance below $10 \mathrm{k} \Omega$.

During the EEG recordings participants were asked to either (i) to relax and engage in no specific mental activity with eyes closed (resting state), or (ii) to engage in achieving a target mental state according to the instructions with eyes closed (experimental state). The presence of an adequate EEG-signal was determined by visual inspection of the raw signal. Artefacts due to eyes opening, eye movement, significant muscle activity, and movements on EEG channels, as well as drowsy episodes (indexed by slowing of background frequencies by $\geq 1 \mathrm{~Hz}$, vertex sharp waves and slow eye movements) were corrected or eliminated by (a) using spatial filtration technique based on zeroing the activation curves of individual Independent Component Analysis (ICA) components that correspond to these artefacts (Vigário, 1997), as well as (b) excluding epochs with excessive amplitude of EEG $(\geq 70 \mu \mathrm{V})$ and excessive fast $(20-35 \mathrm{~Hz}, \geq 35$ $\mu \mathrm{V})$ and slow $(0-1 \mathrm{~Hz}, \geq 50 \mu \mathrm{V})$ frequency activity.

For every session, artifact-free EEG streams were fragmented into consecutive 1-minute epochs, which were bandpass-filtered (Butterworth filter of sixth order) in the alpha $(7-13 \mathrm{~Hz})$ frequency band. Forward and backward filtering were used to eliminate phase shifts. The alpha frequency band was chosen because: (1) it has been repeatedly demonstrated that among different EEG frequency ranges, it is the alpha rhythm that has significant positive correlation with and have a primary role in supporting the SRN (Laufs et al., 2003; Mantini et al., 2007; Jann et al., 2009; Knyazev et al., 2011, 2012; Marino et al., 2019); (2) alpha oscillations dominate human EEG in the absence of external stimuli (Klimesch et al., 2007; Palva \& Palva, 2007; Basar \& Guntekin, 2009; Fingelkurts \& Fingelkurts, 2010, 2014); (3) alpha oscillations have a clear developmental dynamic in spontaneous EEG: children younger than 3 years normally do not show alpha activity (Basar \& Güntekin, 2009, see also Praetorius, 2009), thereafter it gradually reaches adult expression around 7 years of age (Matousek \& Petersen, 1973; Benninger et al., 1984; Gasser et al., 1988). This dynamic correlates with the development of the SRN (Fair et al., 2008; Thomason et al. 2008), as well as development of the awareness of "points of view" and thus "perspective taking" (Gopnik \& Slaughter, 1991; Povinelli et al., 1996; Asendorf, 2002) and (4) it has been shown that EEG alpha range operational synchrony within the three modules of the SRN correlates significantly with variation of the three aspects of self-consciousness during brain and mind pathologies (Fingelkurts et al., 2012, 2016a; Fingelkurts \& Fingelkurts, 2017a,b, 2018), as well as with Selfhood alterations during meditation (Fingelkurts et al., 2016b,c). 


\subsection{Estimation of the SRN OMs and their strength}

Following previous EEG studies (Fingelkurts et al., 2012, 2016a,b,c, Fingelkurts \& Fingelkurts, 2017a,b, 2018), a particular set of nine operationally synchronized cortical areas was used in the present study $^{3}$ to estimate the operational synchrony strength within the three $\mathrm{OMs}^{4}$ (Fig. 1; frontal OM: F3-Fz-F4; left posterior OM: T5-P3-O1; and right posterior OM: T6-P4-O2).

Several stages of data processing were required in order to estimate operational synchrony strength within every OM. The details of this multistage procedure can be found elsewhere (Fingelkurts \& Fingelkurts, 2008, 2015a). Here we provide only a brief overview of the main steps. During the first step, each local EEG signal was reduced to a temporal sequence of nearly stationary (quasi-stationary) segments of varying duration. To uncover these quasi-stationary segments from the complex nonstationary structure of local EEG signals, an adaptive segmentation procedure was used (Fingelkurts \& Fingelkurts, 2008, 2015a). The aim of such segmentation is to divide each local EEG signal into naturally existing quasi-stationary segments by estimating the intrinsic boundaries among segments - rapid transitional periods (RTPs). RTP is defined as an abrupt change in the analytical amplitude of the EEG signal above a particular threshold derived from modelling studies and statistical analysis (Fingelkurts \& Fingelkurts, 2008, 2015a). It has been proposed that each stationary (homogeneous) segment in the local EEG signal corresponds to a temporary stable microstate - an operation executed by a neuronal assembly (Fingelkurts \& Fingelkurts, 2001; Fingelkurts et al., 2010, 2013). The temporal coupling (synchronization) of such segments among several local EEG recordings then, reflects the synchronization of operations (i.e. operational synchrony) produced by different neuronal assemblies (located in different cortical regions) into the integrated and unified patterns responsible for complex mental operations (Fingelkurts \& Fingelkurts, 2001; Fingelkurts et al., 2010, 2013; see also Freeman \& Kozma, 2000; Kozma \& Freeman, 2009; Freeman et al., 2015).

\footnotetext{
${ }^{3}$ In the current study (as well as in our previous studies on the triad model) we used a set of brain areas that have been established previously to belong to SRN (Fingelkurts \& Fingelkurts, 2011). However, those areas were not chosen arbitrary to be part of the SRN. Nine areas (included in the triad model) emerged naturally as members of 3 most stable task-unrelated spatiotemporal patterns with extremely high strength of operational synchrony. This finding has been replicated in two independent studies with participation of subjects from two different nationalities and two different sensory modalities (for detail, see Fingelkurts \& Fingelkurts, 2011). Two comments are important here: (a) The midline posterior cortex (being the important component of SRN, Frewen et al., 2020) is represented in the triad model by left and right precuneus indicated by P3 and P4 (as was documented in the reference study of Koessler et al., 2009); (b) Typically, occipital areas (or involvement of brain visual systems), indexed by $\mathrm{O} 1$ and $\mathrm{O} 2$, are omitted from the SRN; however, they are quite frequently reported to be part of such network (Gusnard \& Raichle, 2001; Miall \& Robertson, 2006; Mantini et al. 2007, 2011; Whitfield-Gabrieli et al., 2009). One may plausibly speculate that visual brain systems contribute to visual images that accompany self-related processing such as self-image, own body image and representation, autobiographical memories, thinking about or planning aspects of personal future, comprehending narratives, self-reflection, and so on. Basically, visual component is always present in self-processing and selfreflection, as it also follows from the phenomenological reports.

${ }^{4} \mathrm{~A}$ brief overview of studies that clearly establish correlation between EEG activity in a given electrode position and its correspondent brain cortical area can be found in Fingelkurts et al. (2016b; p. 30). These results have been verified through an EEG-MRI sensor system and an automated projection algorithm (Koessler et al., 2009).
} 
The second step of the analysis involved estimation of operational synchrony within every OM. Operational synchrony estimates the statistical level of RTP temporal coupling between two or more local EEG recordings (Fingelkurts \& Fingelkurts, 2008, 2015a). This measure tends toward zero if there is no synchronization between EEG segments derived from every pair of EEG channels, and has positive or negative values where such synchronization exists. Positive values (above upper stochastic threshold) indicate "active" process of coupling of EEG segments (synchronization of EEG segments is observed significantly more often than expected by chance as a result of random shuffling of segments during a computer simulation), whereas negative values (below lower stochastic threshold) mark "active" process of decoupling of segments (synchronization of EEG segments is observed significantly less than expected by chance as a result of random shuffling of segments during a computer simulation) (Fingelkurts \& Fingelkurts, 2008, 2015a). The strength of EEG operational synchrony is proportional to the actual (absolute) value of the measure: the higher this value, the greater the strength of functional connection.

Using the described pair-wise analysis, operational synchrony was identified in several (more than two) channels - synchrocomplexes (SC); these define operational modules - OMs. The criterion for defining an $\mathrm{OM}$ is a sequence of the same synchrocomplexes (SC) during every 1-min epoch, whereas a SC is a set of EEG locations in which each location forms a paired combination with valid values of synchrony with all other EEG locations within the same SC; meaning that all pairs of EEG locations in an SC have to have statistically significant synchrony linking them together (Fingelkurts \& Fingelkurts, 2008, 2015a).

A brief note: it is sometimes claimed that EEG analysis performed at the sensor level is prone to volume conduction and it may present an obstacle in interpreting EEG data in terms of brain functional connectivity. The operational synchrony measure used in the current study has been specifically tested previously through modelling experiments to address this issue. These tests show that the operational synchrony values are sensitive to morpho-functional organization of the cortex as opposed to volume conduction, EEG signal power, and/or choice of the reference electrode (for further details, we refer the reader to Fingelkurts \& Fingelkurts, 2008, 2015a).

\subsection{Statistics}

The strength of functional connectivity within individual OMs was assessed using EEG operational synchrony analysis briefly described in the previous section. The differences in strength of operational synchrony between the rest condition and reaching Up- or Down-regulation of the target states, and also between Up- and Down-regulation of the target states were presented as percent changes from the initial state to a consequent state. The Up-state always preceded the Down-state (see Fig. 2). The statistical significance in the percent change between the states at the group level was assessed using a One-Sample $t$ Test with a null hypothesis maintaining that the change is " 0 " (no change). To arrive at the final average value, at first, all strength values of EEG operational synchrony were averaged within every OM for all 1min EEGs per participant and per trial, then averaged for all three trials, and then averaged for all 
participants (group average). Differences between psychometric tests were assessed by Wilcoxon Signed Rank Test. For correlation analysis of OMs integrity strengths with questionnaire scores, the Pearson Correlation test was used.

Since we were testing multiple pre-defined and pre-planned specific hypotheses based on the existing theory of the triad model of Selfhood, we did not apply any correction for multiple significance testing as it is not generally appropriate in such cases (Perneger, 1998; Schulz \& Grimes, 2005). In such cases a strategy of not making adjustments for multiple comparisons is preferable and more adequate because it leads to fewer errors of interpretation (Rothman, 1990; see also Perneger, 1998; Schulz \& Grimes, 2005). However, in order to measure the stability of the main effects of the study (presented as a percent change from the initial state to a consequent state) across all participants, for every state we calculated the coefficient of variability $(\mathrm{CV}=$ standard deviation/Mean $) . \mathrm{CV}=1$ indicates nearly random process while $\mathrm{CV} \sim 0$ reflects very high stability.

Considering that there were 3 target mental states ("Self", "Me" and "I") with 2 variant each (Up- and Down-regulation) repeated 3 times for 8 participants, a total of 144 trials was registered. However, 5 trials were excluded from the further analysis due to a low quality of achieving the target state (subjective ranking equal or less than 5). Additionally, 45 trials were also excluded due to inadequate subjective content in relation to the required for a successfully achieved mental state (based on introspective verbal reports). Therefore, the final sample for the analysis included 94 trials, which is $34.7 \%$ less than the initial number.

\section{Results}

\subsection{Retrospective and introspective findings}

The first-person retrospective reports indicated that, on average, participants were able to successfully induce and maintain the required target mental states. The mean scores for success rating (on a 0-10 scale) are presented in Table 1. While they were generally high, there is a marked difference between I-down and Self-down states: the highest success rating was obtained for the I-down state and the lowest success ratings for Self-down state (these means differ significantly; Wilcoxon's $t$-test: $z=-2.52, p=0.012$ ).

Table 1. Means for success ratings (and standard deviations) of reaching a given target mental state.

\begin{tabular}{|c|c|c|}
\hline & UP & DOWN \\
\hline "Self" (witnessing agency) & $7.42(1.66)$ & $5.96(1.67)$ \\
\hline "Me" (body representational-emotional agency) & $7.83(1.31)$ & $7.58(1.26)$ \\
\hline "I" (reflective/narrative agency) & $7.50(1.35)$ & $8.25(1.02)$ \\
\hline
\end{tabular}

UP means up-regulation of a given mental state; DOWN means down-regulation.

0-10 scale with 0 denoting "no success at all" and 10 denoting "complete success" rating. 
A qualitative analysis of the content of the introspective verbal reports about the subjective experiences during enhancement or inhibition of the target mental states revealed that participants followed the guiding instructions and managed to achieve the required target mental states in the vast majority of trials ( $N=94$ out of 144). The representative examples of verbal reports for every target mental state are presented in Table 2.

Table 2. Examples of the introspective verbal reports.

\begin{tabular}{ll}
\hline & \multicolumn{1}{c}{ UP } \\
\hline "Self" (witnessing agency) & "During the witnessing state, the whole experience was mostly unified into a \\
& field of vivid experience arising and passing without creating attachment. It \\
& could be described as a kind of merging of senses and thoughts into soup of \\
& experience." "Slight feeling of bliss and wellbeing was present throughout." "I \\
& stayed in an attentive observant state almost all the time." "I was meditating \\
& to connect into my Higher Self, and managed to establish the connection quite \\
& soon. Bodily I was relaxed and also mentally. I was feeling well all the time. " \\
& "I elevate the state of consciousness. I observed how the state of \\
& consciousness fluctuated. Attention stayed quite well on the observing and \\
& observed self." "I felt the presence and wittness something bigger than \\
& myself." "Mind was resting in consciousness itself. Things did not get concepts \\
& etc. Things just existed. Pure consciousness." "The mind was alert and like a \\
& wide space. It was like a consciousness outside the individual limits or like an \\
& ocean of consciousness that connects me into the world. " \\
& "There were few thoughts and analysis, and I really felt that I was present in \\
& my body which was a centre." "I felt the body as vibrating system with flowing \\
"Merrents." "I gained body awareness well from the very beginning. At times I & felt and saw my hands on my knees (although my eyes were closed). My \\
thoughts did not wander." "It felt like the body was a bottle filled with light \\
spreading away." "I was present in the body and observe simultaneously the \\
whole body. I felt pulse of the heart, sense of tight throat when swallowing, \\
the weight of body against the chair etc." "Strong feeling of being in the \\
body." "I was present in the body and its feelings." "I was filling in the whole \\
body with consciousness. The diffenences between sensations were clear, \\
there was titillation, tickling, pressure, pulsation etc. The exprience was very \\
pleasant and relaxing, even enjoyable. The thoughts somehow began to be \\
similar to the sensations of the body as if they also were part of the body, \\
which was a centre."
\end{tabular}
which was a centre."

\begin{abstract}
"Consciously I was not thinking anything, I must have lost the bodily connection." "In that state my life history disappeared, just a vanishing hint about something that actually did not exist. I was not thinking or observing anything." "Empty space with only fragmetns of thoughts." "This felt like becoming more heavy, less bright, like controlled falling asleep." "Heavyness, pleasant fog softening the experience, lack of clarity and brightness, lack of energy, calm and peace." "Sunken into a state where no attention and no awareness were present. The body is slow and everything in me happens slowly." "It was a state that is difficult to describe. The amount of experience seemed minor and it is difficult to say where and to whom the experience happened or did it happen at all." "Experience was empty, that is the best word to describe the state."
\end{abstract}

"A clear out-of-body experience. I felt as I rose and felt the space around me. Time disappeared." "My body boundaries expanded into the whole room and street, connected to the air outside." "During the state the various boundaries of the body and the map of the surroundings dissolved into one open field of experience." "The experience of the body was identified with limitless space, peace and bliss was experienced." "My sense about the body disappeared so that I did not feel in which posture I am, do I sit or lie down. Breathing was loosening me more from my body limits." "The body borders were vague and my head completely disappeared, in its place there was just light and something through which light was being breathed in me or from which I myself was breathing light." "Body or bodily feeling was widening over the body until just a soft motionless feeling without a body was left over." "Body's sensations were born and disappeared in a space that was much bigger than the boundaries of the body. It was difficult to say where the boundary between the body and the limitless space was or would they be one and the same thing. It might be fair to say that instead of the body one is habitating the whole space of experience."

"My mind (mental self-reality) remained quite empty. I did not adhere/grip into the thoughts that every now and then emerged." "I did not keep rationality on; just allowed casual mental contents to appear (without focusing or adhering on them)." "Just noticed some fragments of thought, without a story or judging." "It felt like the mind was a mirror reflecting the content that arose, not grasping the thoughts in any way." "I was resting in empty mind, every now and then thoughts, images etc. came but they were allowed to come and go." "Characteristic for the state was being present as an individual being, but the reactivity of the mind was missing, the inner commentator was quiet and the contents of experience could freely change and flow."
"I was able to stay in my self-thoughts almost all the time. The inner experiences and events." "I was thinking myself, seeing, hearing and conversing." "I linguistically focused on the sense of self while reflecting on the various situations and myself in those moments." "Continuous talkative stream of thoughts related to myself." "Continuous speach-like stream of thoughts regarding mainly myself and my actions." "I called up my psychological self. I observed what kind of characteristics are related to it and used inner speech to help me. I named with internal speech different kinds of phenomena that rose up, like tension, tickling, mental images, feelings etc."

"Rest was pretty normal." "No specific commentary." "Nothing in particlular." "Nothing much actually. " "Sitting with the eyes closed, peaceful relaxed state, not doing anything at all." "I tried to do nothing. The experience was relaxed and open."

Table 3 presents alterations in subjective experiences during the induced target mental states (in relation to the baseline resting condition) measured by the nine standardised questionnaires. Changes in the expression of twenty phenomenological factors were assessed for Up- and Down-regulation of the three metal states: "Self", "Me", and "I". None of the states led to changes in the "Anxiety" or "Depression" factors; however, the expression of other factors either increased or decreased depending on the Up- or Down-regulation of the target mental states. In the vast majority of cases statistically significant changes followed the intended meaning of the achieved states (see Table 3). However, there were several not 
immediately apparent dependences: for example, the factor "Here \& Now" decreased during Me-down and Idown states. Further, "Concatenation of thoughts" decreased during I-up state, and "Speed of thoughts" increased during I-up state.

Table 3. Alterations in subjective experiences during the induced target mental states measured by the standardised questionnaires.

\begin{tabular}{|c|c|c|c|c|c|c|}
\hline & \multicolumn{2}{|c|}{ "Self" (witnessing agency) } & \multicolumn{2}{|r|}{ "Me" (embodiment) } & \multicolumn{2}{|c|}{ "I" (reflective/narrative agency) } \\
\hline & UP & DOWN & UP & DOWN & UP & DOWN \\
\hline Anxiety ${ }^{a}$ & $(z=-0.37, p=0.715)$ & $(z=-0.68, p=0.496)$ & $(z=0.00, p=1.000)$ & $(z=-0.38, p=0.705)$ & $(z=-0.92, p=0.357)$ & $(z=-0.63, p=0.527)$ \\
\hline Depression ${ }^{b}$ & $(z=-1.63, p=0.102)$ & $(z=0.00, p=1.000)$ & $(z=-1.41, p=0.157)$ & $(z=-1.34, p=0.180)$ & $(z=-0.53, p=0.593)$ & $(z=-0.53, p=0.593)$ \\
\hline Self-Concept Clarity ${ }^{c}$ & $\uparrow(z=-2.23, p=0.026)$ & $(z=-1.48, p=0.140)$ & $(z=-1.21, p=0.225)$ & $(z=-1.27, p=0.205)$ & $\uparrow(z=-2.05, p=0.041)$ & $(z=-1.78, p=0.075)$ \\
\hline Involuntariness ${ }^{d}$ & $(z=-0.73, p=0.465)$ & $(z=-1.26, p=0.207)$ & $(z=-0.14, p=0.891)$ & $\uparrow(z=-2.37, p=0.018)$ & $(z=-0.35, p=0.725)$ & $\downarrow(z=-1.37, p=0.047)$ \\
\hline Effortlessness ${ }^{d}$ & $(z=-0.27, p=0.785)$ & $\downarrow(z=-2.03, p=0.042)$ & $(z=-0.18, p=0.854)$ & $\downarrow(z=-1.98, p=0.048)$ & $\downarrow(z=-2.00, p=0.046)$ & $(z=-0.68, p=0.495)$ \\
\hline Rumination $^{\mathrm{e}}$ & $(z=0.00, p=1.000)$ & $(z=-0.52, p=0.600)$ & $(z=-0.68, p=0.498)$ & $(z=-0.53, p=0.598)$ & $(z=-1.62, p=0.105)$ & $\downarrow(z=-2.03, p=0.042)$ \\
\hline Reflection $^{\mathrm{e}}$ & $(z=0.00, p=1.000)$ & $(z=-0.41, p=0.683)$ & $(z=-0.14, p=0.892)$ & $(z=-0.21, p=0.834)$ & $\uparrow(z=-2.03, p=0.042)$ & $(z=-0.82, p=0.414)$ \\
\hline Observing ${ }^{f}$ & $\uparrow(z=-2.02, p=0.043)$ & $\downarrow(z=-2.03, p=0.042)$ & $\uparrow(z=-2.01, p=0.044)$ & $(z=-1.34, p=0.181)$ & $(z=-1.90, p=0.058)$ & $(z=-0.42, p=0.671)$ \\
\hline Ownership ${ }^{\mathrm{g}}$ & $\uparrow(z=-2.24, p=0.025)$ & $\downarrow(z=-2.12, p=0.034)$ & $\uparrow(z=-2.06, p=0.039)$ & $\downarrow(z=-2.04, p=0.041)$ & $(z=-1.41, p=0.157)$ & $(z=-0.27, p=0.785)$ \\
\hline Self-Location ${ }^{\mathrm{g}}$ & $(z=-0.58, p=0.564)$ & $(z=-1.19, p=0.236)$ & $\uparrow(z=-2.07, p=0.038)$ & $\downarrow(z=-2.22, p=0.026)$ & $\downarrow(z=-2.26, p=0.024)$ & $(z=-0.43, p=0.666)$ \\
\hline Agency ${ }^{g}$ & $(z=-1.41, p=0.157)$ & $(z=-0.74, p=0.461)$ & $\uparrow(z=-2.12, p=0.034)$ & $\downarrow(z=-2.06, p=0.039)$ & $(z=-1.63, p=0.102)$ & $(z=-0.37, p=0.713)$ \\
\hline Body image ${ }^{h}$ & $(z=-0.82, p=0.414)$ & $(z=-1.73, p=0.414)$ & $\uparrow(z=-2.00, p=0.046)$ & $\downarrow(z=-2.06, p=0.039)$ & $(z=0.00, p=1.000)$ & $(z=-0.56, p=0.577)$ \\
\hline Body perception ${ }^{h}$ & $(z=-0.58, p=0.564)$ & $(z=-1.84, p=0.066)$ & $\uparrow(z=-2.12, p=0.034)$ & $\downarrow(z=-2.21, p=0.028)$ & $\downarrow(z=-2.25, p=0.024)$ & $(z=-0.97, p=0.334)$ \\
\hline Body orientation ${ }^{\mathrm{h}}$ & $(z=-1.00, p=0.317)$ & $(z=-1.34, p=0.180)$ & $(z=-1.00, p=0.317)$ & $\downarrow(z=-2.06, p=0.039)$ & $(z=0.00, p=1.000)$ & $(z=0.00, p=1.000)$ \\
\hline Here \& now ${ }^{i}$ & $\uparrow(z=-1.84, p=0.050)$ & $\downarrow(z=-2.06, p=0.039)$ & $(z=-1.29, p=0.197)$ & $\downarrow(z=-2.12, p=0.034)$ & $\downarrow(z=-1.69, p=0.050)$ & $\downarrow(z=-2.04, p=0.041)$ \\
\hline The future ${ }^{i}$ & $(z=-1.00, p=0.317)$ & $(z=-1.63, p=0.102)$ & $(z=-1.34, p=0.180)$ & $(z=-1.58, p=0.114)$ & $(z=-0.34, p=0.734)$ & $\downarrow(z=-1.84, p=0.050)$ \\
\hline The past ${ }^{i}$ & $(z=-1.00, p=0.317)$ & $(z=-1.84, p=0.066)$ & $(z=-0.82, p=0.414)$ & $(z=-1.22, p=0.223)$ & $(z=-0.63, p=0.528)$ & $\downarrow(z=-2.02, p=0.043)$ \\
\hline Concatenation of thoughts & $(z=-0.58, p=0.564)$ & $(z=-0.51, p=0.610)$ & $(z=-0.32, p=0.752)$ & $(z=-1.19, p=0.235)$ & $\downarrow(z=-2.39, p=0.017)$ & $(z=-0.41, p=0.684)$ \\
\hline Thoughts continuity ${ }^{i}$ & $(z=-1.07, p=0.285)$ & $(z=-0.21, p=0.832)$ & $(z=-1.13, p=0.257)$ & $\downarrow(z=-2.06, p=0.039)$ & $\uparrow(z=-2.21, p=0.027)$ & $\downarrow(z=-2.23, p=0.026)$ \\
\hline Speed of thoughts ${ }^{i}$ & $(z=-1.34, p=0.180)$ & $(z=-1.24, p=0.216)$ & $(z=-0.40, p=0.686)$ & $(z=-1.60, p=0.109)$ & $\uparrow(z=-2.23, p=0.026)$ & $(z=-0.40, p=0.686)$ \\
\hline
\end{tabular}

Statistically significant changes (Wilcoxon's $t$-test) in relation to a baseline resting state are indicated by the arrows pointing up or down and a bold font. UP means up-regulation of a

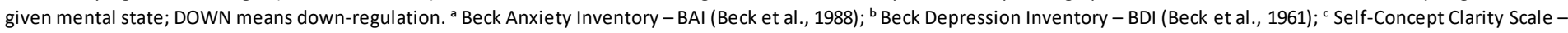

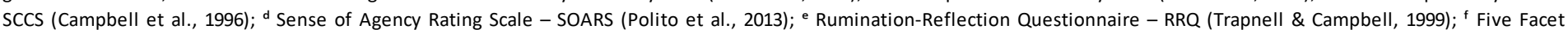
Mindfulness Questionnaire - FFMQ (Baer et al., 2006); ${ }^{\mathrm{E}}$ Embodiment Questionnaire - EQ (Aymerich-Franch et al., 2015); ${ }^{\mathrm{h}}$ The Sense of Body - SB (in-house produced questionnaire,

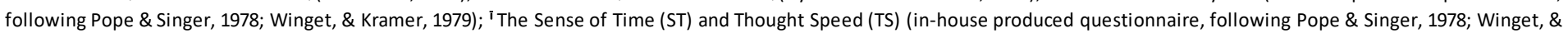
Kramer, 1979).

\subsection{Neurophenomenological findings}

We observed a systematic increase or decrease in the strength of EEG operational synchrony (measured as percent change from the preceding state) within each respective OM every time participants mentally Upor Down-regulate corresponding three aspects of Selfhood in a controlled manner (Fig. 3). These percent changes were statistically significant (One-Sample $t$-test: $t=2.45 p=0.044$ for anterior OM Up-state; $t=$ $4.07 p=0.007$ for anterior OM Down-state; $t=2.44 p=0.044$ for right posterior OM Up-state; $t=-4.12 p=$ 0.004 for right posterior OM Down-state; $t=2.5 p=0.041$ for left posterior OM Up-state; $t=-2.75 p=$ 0.029 for left posterior OM Down-state). In other words, a strong feeling of, for example, enhanced embodiment was accompanied by the statistically significant increase of operational synchrony in the rightposterior OM, while a feeling of disembodiment or out-of-body experience was associated with statistically significant decrease of the synchrony in the same right-posterior OM (Fig. 3). The same dynamics were present for the other two OMs relative to the expression of the corresponding to them mental states (see

Table 2 and Table 3). 


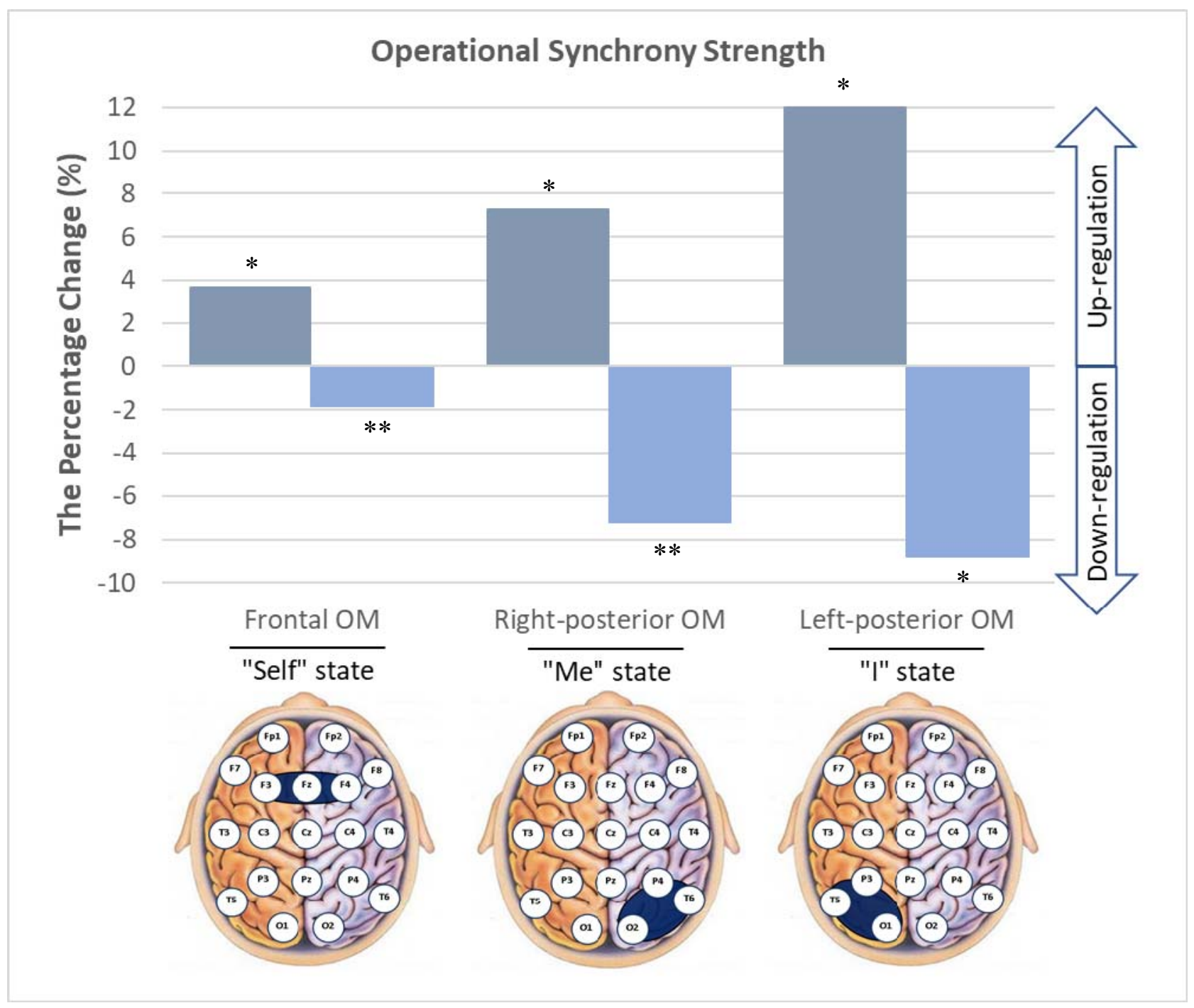

Figure 3. Percent change from the preceding state in the strength of operational synchrony within the three target OMs of the brain self-referential network during Up- and Down-regulation of three phenomenological states ("Self", "Me", and "I"). The $Y$-axis presents percent change. The $X$-axis represents the three OMs corresponding to three phenomenological states: "Self" (witnessing agency), "Me" (body-representational agency) and "I" (reflective/narrative agency). The schematic cortex maps below the graphs indicate the positions of OMs (dark blue shapes). Abbreviations: OM: operational module. * or ** indicate $p<0.05$ or $p<0.01$ (One-Sample $t$-test with a null hypothesis maintaining that the change is " 0 " no change).

These effects were quite stable across participants and target states as is indicated by the coefficient of variability (CV) of the group results (see Table 4). A CV equal to one indicates nearly random process while a CV less than one reflects relatively high stability.

Correlations between the strength of EEG operational synchrony within every OM and expression of the phenomenological factors (indexed by the standardised questionnaires) are presented in Table 5. For this analysis only statistically significant changes (marked in Table 3$)$ were taken into account $(N=18)$. Increased "Self-Concept Clarity" was positively correlated with increased frontal ("Self") as well as left posterior ("I") OM synchrony. Increased sense of "Involuntariness" was negatively correlated with decreased 
strength of synchrony of the right posterior ("Me") OM. The sense of "Effortlessness" decreased along with decrease (positive correlation) of frontal ("Self") OM strength. An increase in feeling of "Observing" was positively correlated with increased strength of frontal ("Self") $\mathrm{OM}$ and right posterior ("Me") $\mathrm{OM}$ synchrony, while a decrease in "Observing" feeling was positively correlated with decreased strength of the frontal ("Self") OM synchrony. An increased sense of "Ownership" was positively correlated with increased strength of the frontal ("Self") and right posterior ("Me") OMs synchrony, while a reversal, decreased sense of "Ownership" was positively correlated with decreased strength of the frontal ("Self") and right posterior ("Me") OMs synchrony. An increased sense of "Self-Location", "Agency", "Body image", and "Body perception" were positively correlated with increased strength of the right posterior ("Me") OM synchrony. An increase in "Here \& Now" sense was accompanied (positive correlation) with increase in the strength of frontal ("Self") OM synchrony, while a decrease of this sense was positively correlated with decrease of the strength of frontal ("Self") OM synchrony. A decrease in the "Concatenation of thoughts" was negatively correlated with increase in strength of the left posterior ("I") OM synchrony (see Table 5).

Table 4. Coefficient of variability for the averaged percent change in the strength of operational synchrony across all particpants for six studied phenomenological states.

\begin{tabular}{lll}
\hline Target state "Me": & Embodiment-UP & 0.5 \\
Target state "Me": & Embodiment-DOWN & 0.6 \\
Target state "I": & Reflection-UP & 0.6 \\
Target state "I": & Reflection-DOWN & 0.6 \\
Target state "Self": & Witnessing-UP & 0.7 \\
Target state "Self": & Witnessing-DOWN & 0.6 \\
\hline
\end{tabular}

\begin{tabular}{|c|c|c|c|c|c|c|}
\hline & \multicolumn{3}{|c|}{ "Self" (witnessing agency) } & "Me" (embodiment) & \multicolumn{2}{|r|}{ "I" (reflective/narrative agency) } \\
\hline & $\begin{array}{r}\text { UP } \\
\text { (frontal OM strength) }\end{array}$ & $\begin{array}{r}\text { DOWN } \\
\text { (frontal OM strength) }\end{array}$ & $\begin{array}{r}\text { UP } \\
\text { (right posterior OM strength) }\end{array}$ & $\begin{array}{r}\text { DOWN } \\
\text { (right posterior OM strength) }\end{array}$ & $\begin{array}{r}\text { UP } \\
\text { (left posterior OM strength) }\end{array}$ & $\begin{array}{r}\text { DOWN } \\
\text { (left posterior OM strength) } \\
\end{array}$ \\
\hline Self-Concept Clarity & $R=0.98, p=0.019$ & & & & $R=0.78, p=0.022$ & \\
\hline Involuntariness & & & & $R=-0.78, p=0.021$ & & $R=0.32, p=0.439$ \\
\hline Effortlessness & & $R=0.92, p=0.004$ & & $R=0.32, p=0.448$ & $R=-0.58, p=0.129$ & \\
\hline Rumination & & & & & & $R=0.24, p=0.574$ \\
\hline Reflection & & & & & $R=-0.32, p=0.444$ & \\
\hline Observing & $R=0.99, p=0.012$ & $R=0.88, p=0.009$ & $R=0.88, p=0.009$ & & & \\
\hline Ownership & $R=0.96, p=0.044$ & $R=0.75, p=0.032$ & $R=0.87, p=0.011$ & $R=0.71, p=0.048$ & & \\
\hline Self-Location & & & $R=0.97, p=0.001$ & $R=-0.53, p=0.173$ & $R=-0.47, p=0.241$ & \\
\hline Agency & & & $R=0.98, p=0.001$ & $R=0.02, p=0.962$ & & \\
\hline Body image & & & $R=0.95, p=0.001$ & $R=0.32, p=0.436$ & & \\
\hline Body perception & & & $R=0.97, p=0.001$ & $R=0.02, p=0.967$ & $R=-0.38, p=0.354$ & \\
\hline Body orientation & & & & $R=-0.34, p=0.409$ & & \\
\hline Here \& now & $R=0.96, p=0.042$ & $R=0.76, p=0.047$ & & $R=0.31, p=0.456$ & $R=-0.02, p=0.959$ & $R=0.37, p=0.372$ \\
\hline The future & & & & & & $R=-0.49, p=0.216$ \\
\hline The past & & & & & & $R=0.47, p=0.241$ \\
\hline Concatenation of thoughts & & & & & $R=-0.75, p=0.032$ & \\
\hline Thoughts continuity & & & & $R=0.18, p=0.675$ & $R=-0.22, p=0.598$ & $R=0.52, p=0.186$ \\
\hline Speed of thoughts & & & & & $R=0.11, p=0.792$ & \\
\hline
\end{tabular}

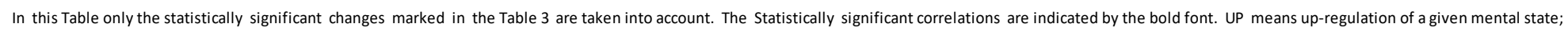
DOWN means down-regulation. EEG: electroencephalography. OM: operational module. 
However, estimation of the statistical significance of the correlation is not enough to understand the magnitude or strength of such a correlation. To obtain an estimate of such strength, the correlation coefficients were squared, resulting in the values $R^{2}$ (the coefficient of determination - $C D$ ) that represent the proportion of common variation in the two variables. Multiplied by 100 , this proportion of variance indicates the percentage of variance that is explained by the correlation function. The values of CD are presented in Table 6 for all significant correlations highlighted in Table 5. The CD indicates that anywhere from 56\% to $98 \%$ of the operational synchrony strength variance in any given OM is coupled/associated with a variance in a given phenomenological aspect expression. The only exception was the right posterior OM strength during Me-down state and the sense of "Ownership", where the CD was $47 \%$. Generally, a CD $\geq 50 \%$ is considered to be indicative of good dependency of one variable with another.

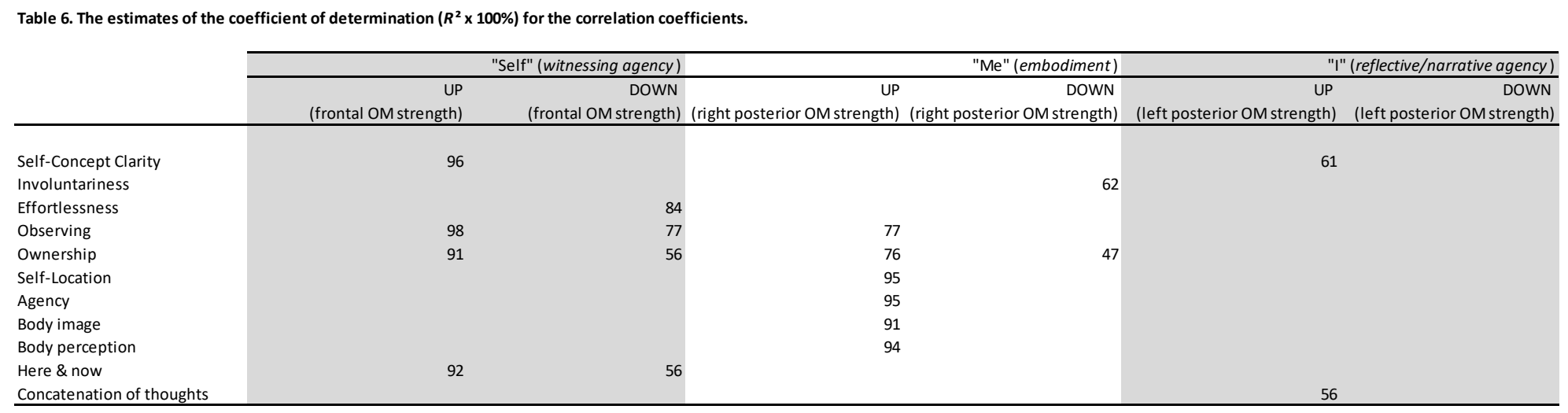

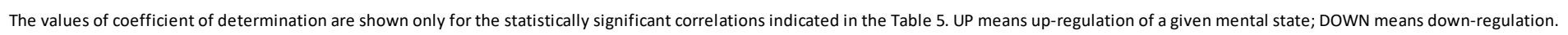

Figure 4 presents dynamics of the strength of operational synchrony in the NON-target OMs (measured as percent change from the preceding state) during Up- and Down-regulation of three target mental states ("Self", "Me", and "I"). All changes were statistically non-significant. In all except the left posterior OM (while targeting the Self-up state) the changes were in the same direction as for the target states, though they were far less pronounced than in the target states (see Fig. 3).
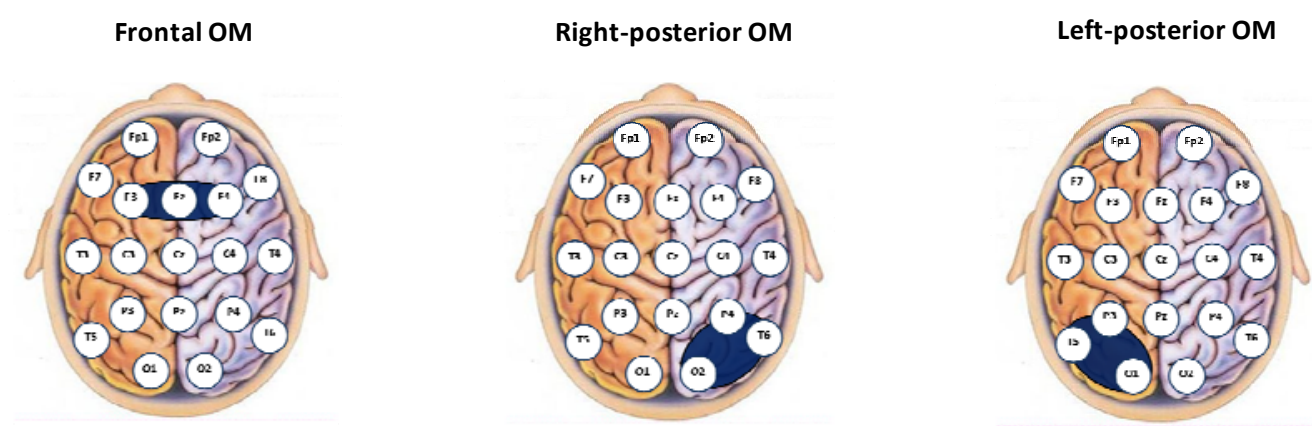

\begin{tabular}{|c|c|c|c|c|c|c|}
\hline & Self UP-regulation & Self DOWN-regulation & Me UP-regulation & Me DOWN-regulation & IUP-regulation & I DOWN-regulation \\
\hline Frontal OM & & & $\uparrow(t=1.48, p=0.189)$ & $\downarrow(t=-0.75, p=0.477)$ & $\uparrow(t=2.27, p=0.058)$ & $\downarrow(t=-1.10, p=0.308)$ \\
\hline ight-posterior OM & $\uparrow(t=0.45, p=0.680)$ & $\downarrow(t=-0.01, p=0.999)$ & & & $\uparrow(t=0.51, p=0.626)$ & $\downarrow(t=-1.83, p=0.110)$ \\
\hline eft-posterior OM & $\downarrow(t=-1.6, p=0.207)$ & $\downarrow(t=-0.66, p=0.536)$ & $\uparrow(t=1.02, p=0.348)$ & $\downarrow(t=-0.63, p=0.548)$ & & \\
\hline
\end{tabular}


Figure 4. Percent change from the preceding state in the strength of operational synchrony within the NON-target OMs of the brain self-referential network during Up- and Down-regulation of three phenomenological states ("Self", "Me", and "I"). The target OMs are indicated on the schematic cortex maps. Abbreviations: OM: operational module; $\uparrow:$ increase in the percent change; $\downarrow$ : decrease in the percent change; One-Sample $t$-test and $p$ values are indicated in brackets.

\section{Discussion}

The main positive finding of this study was that every time participants mentally and in a controlled manner willfully up-regulated the expression of "Self" (witnessing agency), "Me" (body representationalemotional agency) or "I" (reflective/narrative agency), the functional integrity (indexed by EEG operational synchrony) of the corresponding SRN OMs increased significantly, and conversely, wilful down-regulation of the "Self", "Me" or "I" expression resulted in a significant decrease of the functional integrity of the respective SRN OMs (Fig. 3). The observed increases or decreases in the functional integrity of the SRN OMs were predictably coupled with participants' self-description of alterations in the phenomenological experience during up- or down-regulation of "Self", "Me", and "I" states (Table 2), and significantly correlated with phenomenological factors estimated by a set of standardised questionnaires (Table 5 and 6 ). Taken together, these findings suggest a causative relation between the three phenomenological aspects of Selfhood and related to them three OM of the brain SRN. In other words, one cannot change phenomenological properties of Selfhood at will, without evoking specific changes in the neurodynamics of the corresponding OMs, as the two seem to be inexorably linked in long-term meditators.

According to first-person retrospective reports (Table 1) the target state that participants found the easiest to achieve was the I-down state (the highest success rating), while the Self-down state was the hardest (the lowest - though still high enough - success rating). These ratings may be readily explained by the following: long-term experienced mediators are used to regularly and routinely downregulating the "I" state (which is normally manifested by the self-reflection and narration). Indeed, most contemplative practises (meditation techniques) require that meditators learn to disrupt any sort of inner narrative and reflection on the past, or worrying/fantasizing about the future, through sustained attention on the present moment, all in an effort to reach equanimity and stillness of mind (Dalai Lama, 1991; Austin, 2000; Harvey, 2012; Nash et al., 2013). With time and sustained effort such skills become second nature and require very little effort. On the other hand, successfully achieving a Self-down state and associated loss of the "witnessing observer" where only wakeful but contentless (nonintentional) consciousness (Forman, 1998) that is not tied to a phenomenal first-person perspective is present (Metzinger, 2020), is much harder to achieve and describe, since there is neither content nor the phenomenal self to report about (Travis \& Pearson, 2000; Josipovic 2019). Indeed, the first-person introspective reports (see Table 2) of the participants of the current study clearly indicated this difficulty: "It was a state that is difficult to describe. The amount of experience seemed minor and it is difficult to say where and to whom the experience happened or did it happen at all." 
"Experience was empty, that is the best word to describe the state." Such descriptions are in line with evidence from previous research on phenomenological descriptions of (i) selfless state during meditation (Dor-Ziderman et al., 2013; Ataria et al., 2015), (ii) dreamless sleep experience (Thompson, 2015; Windt, 2015), and (iii) drug-induced self-dissolution, as for example under influence of 5-MeO-DMT (Nour \& Carhart-Harris, 2017; Millière, 2017, 2020).

Capitalising on the main findings of the present study (Fig. 3 and Table 2, 3, 5 and 6), and keeping in mind the neurophenomenological approach (Gallagher, 2003b; Lutz \& Thompson, 2003; Fazelpour \& Thompson, 2015), we now turn our attention to an in-depth analysis of the six mental states achieved by the study participants: Me-up, Me-down, I-up, I-down, Self-up, and Self-down.

\subsection{Up-regulation of the body representational-emotional agency (Me-up state)}

During Me-up state participants were instructed to focus on the sense of body, on the image of their body, on any tiny bodily sensations, on the related emotional feelings; to sense the position, posture or micromovement; to sense that oneself centered in their body from which one is experiencing the world. The overwhelming majority of participants reported a high rate of success in reaching and maintaining this state of hyperembodiment (Table 1). Upon achieving this state, participants described it as: "There were few thoughts and analysis, and I really felt that I was present in my body which was a centre"; "I was present in the body and observe simultaneously the whole body" or "The thoughts somehow began to be similar to the sensations of the body as if they also were part of the body, which was a centre" (Table 2). During this state the phenomenological sense of "Observing", "Ownership", "Self-location", "Agency" (as a physical agency), "Body image", and "Body perception" (but not "Body orientation") ${ }^{5}$ increased significantly in comparison with the resting baseline state (Table 3). All these phenomenal features have been proposed to be central for Selfhood embodiment, allowing a globalized form of self-identification with the body as a whole (as opposed to mere ownership of body parts; Blanke \& Metzinger, 2009; Metzinger, 2013), spatiotemporal self-location (centredness from within the body upon the world; Vogeley \& Fink, 2003; Zahavi, 2006), and a geometrical first-person perspective ${ }^{6}-$ a point of origin of a subject's visuospatial perspective (including a perceived environment from the subject's own location ${ }^{7}$; Bermudez, 1998; Schwenkler, 2014).

It is generally agreed that together, these features build the basis of our "material me" (Tsakiris et al., 2007; Herbert, 2015) and the sense of for-me-ness (Gallagher, 2000; Aspell et al., 2009; Gallagher \& Zahavi,

\footnotetext{
${ }^{5}$ The observation that "body orientation" was not affected may be explained by the fact that it belongs to the body schema (as opposed to the body image or body percept; Gallagher, 1986; see also de Vignemont, 2010; Pitrona \& de Vignemonta, 2017) that may function differently from the body image.

${ }^{6}$ According to Metzinger (2013), such first-person perspective typically includes an egocentric spatial frame of reference, coupled with a global body representation, and a geometrical perspective originating within this body representation. In other words, there is a center of projection that functions as the geometrical origin of the passive perspective (Metzinger, 2013).

${ }^{7}$ In this context, the environmental landmarks are not just perceived as located with respect the location of the point of origin of the frame of reference - the visuospatial perspective - they are perceived as located with respect to "me", where "me" refers to the subject as such (Cassam, 1997; Hurley, 1998; Bermúdez, 2001; Noë, 2005).
} 
2015), thus laying the foundation for a basic, minimal and pre-reflective ${ }^{8}$ aspect of self (Zahavi, 1999; Gallagher, 2005; Hohwy, 2007; Haanila, 2015). Recently, this has been framed within the predictive coding account of self (Friston, 2011; Seth et al., 2012; Hohwy, 2013; Apps \& Tsakiris, 2014), according to which the prediction error (and uncertainty) of the self-model system is not explained away post-hoc, but instead constantly and across all levels of the self-model (Friston, 2012; Hohwy, 2013). This explains why a sense of mineness is always implicit in the flow of information within the hierarchical generative self-model, and can correspondingly be experienced in the same way for actions, perceptions and thoughts (Limanowski \& Blankenburg, 2013). Importantly, this also means that such basic or minimal aspect of Selfhood is the result of an ongoing, dynamic process, and not a static representation (Gallagher, 2005).

Since embodiment heavily relies on the interoception, exteroception, proprioception, and a spatiotemporal reference frame (Critchley et al., 2004; Metzinger, 2004; Carruthers, 2008; Craig, 2009; Blanke \& Metzinger, 2009; Tsakiris et al., 2011), as well as supports related emotional states ${ }^{9}$ (Craig, 2009; Damasio, 2010; Harrison et al., 2010; Nummenmaa et al., 2014), it is not surprising that the functional integrity of the right SRN OM increased (Fig. 3) during up-regulation of the embodiment state. This $\mathrm{Me}$ module is formed by the set of right posterior brain areas and systems reported to be involved in the interoceptive awareness, awareness of intended and actual movements, as well as multisensory integration underlying all aspects of global body ownership relevant to Selfhood. This involves areas like right inferior parietal cortex, right temporo-parietal-junction, right posterior insula, and other right occipito-temporalposterior subnets (Damasio, 1999; Downing et al., 2001; Farrer \& Frith, 2002; Farrer et al., 2003; Haggard et al., 2003; Vogeley \& Fink, 2003; Critchley et al., 2004; Blanke \& Mohr, 2005; Arzy et al., 2006; De Ridder et al., 2007; Jeannerod, 2007; Tsakiris et al., 2008; Blanke \& Metzinger, 2009; Ionta et al. 2011). The increased functional integrity of the right SRN OM (Me-module) was markedly correlated with the feeling of hyperembodiment indicated by the increased correlation between the values of Me-module's integrity and expression of such phenomenological features as "Observing", "Ownership", "Self-location", "Physical agency", "Body image", and "Body perception" (see Table 5 and 6). This suggests that the clearer the subjective experience of self-embodiment (a determinate volume in space and time, normally localized within the bodily boundaries as represented; Blanke \& Metzinger, 2009), the stronger the functional integrity within the brain Me-module (right SRN OM; Fig. 1).

At the same time, it has been widely recognised that whilst embodiment may be causally enabling, it is not a constitutive condition for phenomenal Selfhood (Blanke \& Metzinger, 2009; Metzinger, 2013;

\footnotetext{
${ }^{8}$ The term "pre-reflective" is referring to the aspect of self-awareness that is independent of explicit cognition and linguistic abilities (Legrand, 2006; Blank, \& Metzinger, 2009; Zahavi, 2014) and is immediately and constantly present to a subject (Hohwy, 2010; Seth et al., 2012). It has been argued that such pre-reflective aspect emerges from the experience that my body is not just part of the physical world, but also and for the most is the "vehicle" that enables one to be oneself in this world (Merleau-Ponty, 1962; Varela et al., 1994) as a unified, situated living body - so called a "sensorimotor unity anchored to its world" (Bermúdez et al., 1998; Friston, 2011; Hohwy, 2013; Limanowski \& Blankenburg, 2013).

${ }^{9}$ Both classic (James, 1884) and modern (Levenson, 2003; Barrett et al., 2007; Damasio \& Carvalho, 2013) emotional processing models maintain that subjective emotional feelings are associated with the perception of emotion-related bodily states (Seth, 2013; Nummenmaa et al., 2014).
} 
Gallagher, 2013), as states of decreased embodiment, bodilessness or out-of-body experience have clearly indicated (Green, 1968; Cicogna \& Bosinelli, 2001; Blanke et al., 2002; Windt, 2014; Ataria et al., 2015; Millière, 2020). The state of disembodiment is discussed in the following section.

\subsection{Down-regulation of the body representational-emotional agency (Me-down state)}

During Me-down state participants were instructed to focus on a sense of open space without the bodily dimension; concentrate on the absence of the body physical image and try to experience oneself wider, expanded, less physically bounded, bodiless as in out-of-body experience. The vast majority of participants reported a high rate of success in reaching and maintaining this state of disembodiment (Table 1). Upon achieving this state, participants characterise it as: "A clear out-of-body experience. I felt as I rose and felt the space around me. Time disappeared"; "The experience of the body was identified with limitless space, peace and bliss was experienced" or "It was difficult to say where the boundary between the body and the limitless space was or would they be one and the same thing. It might be fair to say that instead of the body one is habitating the whole space of experience" (Table 2). Such phenomenological descriptions were in line with the number of concrete phenomenological aspects ("Effortlessness", "Ownership", "Body selflocation", "Physical agency", "Body image", "Body perception", "Body orientation", "Here \& now", and "Thoughts continuity") that decreased significantly during this state when compared to the baseline resting condition (Table 3). At the same time, the phenomenological sense of "Involuntariness" increased significantly (Table 3). These phenomenological observations clearly point to the fact that participants in Me-down state do not experience themselves as a full-fledged embodied entity - they have diminished or no (a) automatic and immediate sense of physical agency (which is corroborated by the increased sense of involuntariness - lack of deliberate control; feeling that body sensations are not caused by oneself; Gallagher, 2000, 2005), (b) first-order experiential sense of ownership - that it is me who owns the body (Gallagher, 2000; Tsakiris, 2010), and (c) body self-location, body image and body schema (Gallagher, 1986). Additionally, the lack of phenomenological "Hear \& now" indicates that during Me-down sate participants were not oriented in neither time or space, both of which have been transiently suspended. Spatiotemporal self-location is considered to be one of the hallmarks of self-embodiment ${ }^{10}$ (Windt, 2015; Metzinger, 2020) and its lack is often reported during bodiless states (Kjellgren, et al., 2008; BerkovichOhana et al., 2013; Ataria et al., 2015; Wittmann, 2015).

The observed thought discontinuity or lack of thought during this disembodiment (Me-down) state seems unexpected since it is not directly related to the phenomenal features of the brain SRN Me-module (Fingelkurts \& Fingelkurts, 2017a,b, 2018), therefore it warrants additional discussion. One plausible explanation could be within a pattern theory of self (Gallagher, 2013), according to which different aspects/features/components of self are not simply an additive list of features, but rather is a set of

10 Though, according to Windt (2015), the phenomenal "now" does not appear to carry the same weight as the phenomenal "here", at least intuitively. 
components dynamically interrelated in a pattern forming a complex emergent gestalt (Gallagher \& Daly, 2018). This means that interventions that affect one aspect or component of complex Selfhood, will lead via dynamical interrelation to some changes in others (we will return to this issue in the Section 4.7). Such an interpretation is supported not only by the phenomenological evaluations of the present study (Table 3), but also by the phenomenological records of altered states of self-consciousness, where embodiment distortions were accompanied by the distortions in thought process (Blakemore et al., 2000; Parnas \& Handest, 2003; Ataria et al., 2015; Millière, 2017, 2020; Pollan, 2018).

Since normally embodiment is generated through integration of interoception, exteroception, proprioception, and a spatiotemporal reference frame (Critchley et al., 2004; Metzinger, 2004; Carruthers, 2008; Craig, 2009; Blanke \& Metzinger, 2009; Tsakiris et al., 2007, 2011), the sense of disembodiment or bodilessness is by contrast the result of disruption of such integration (Giummarra et al., 2008; Blanke \& Metzinger, 2009; Asai et al., 2011; Apps \& Tsakiris, 2014; Graham et al., 2014). Indeed, as it has been shown in the current study, the Me-down state was accompanied by the certain level of functional disintegration of the corresponding brain right SRN OM (Fig. 3). As mentioned previously, this Me-module is formed by the set of right posterior brain areas and systems (Fig. 1) that have been implicated to be involved in interoceptive awareness, geometrical first-person perceptiveness, awareness of intended and actual movements, as well as multisensory integration underlying all aspects of global body ownership relevant to Selfhood (Damasio, 1999; Downing et al., 2001; Farrer \& Frith, 2002; Farrer et al., 2003; Haggard et al., 2003; Vogeley \& Fink, 2003; Critchley et al., 2004; Blanke \& Mohr, 2005; Arzy et al., 2006; De Ridder et al., 2007; Jeannerod, 2007; Tsakiris et al., 2008; Blanke \& Metzinger, 2009; Ionta et al. 2011). Furthermore, decreased functional integrity of the right SRN OM (Me-module) was markedly correlated with feeling of disembodiment, as indicated by significant correlation between decreased values of Memodule's integrity and decreased expression of such phenomenological feature as "Ownership", and also increased expression of the phenomenological feature of "Involuntariness" (see Table 5 and 6). This later negative correlation indicates that the stronger the subjective experience of lack of deliberate control (feeling that body sensations happen automatically without the intervention of a willing self; Gallagher, 2000, 2005), the weaker the functional integrity within the brain Me-module (right SRN OM).

It must be noted that detailed analysis of the totality of phenomenological reports describing the Medown state (Table 2) revealed that even during disembodiment there was some kind of phenomenal certitude, some experience of being a self - as a separate entity having the experience and a potential for possessing knowledge (thus being an epistemic agent; Metzinger, 2013, 2020). This pointed to the fact that other components of complex Selfhood were preserved. In the following sections we will analyse the remaining components of the triad model of Selfhood (reflective/narrative agency and witnessing agency).

\subsection{Up-regulation of the reflective-narrative agency (I-up state)}


During I-up state participants were instructed to focus on reflecting upon oneself; analyse oneself by silently talking to oneself about oneself; facilitate the labelling of every self-experience or self-memory one may have. The overwhelming majority of participants reported a high rate of success in reaching and maintaining this state of increased self-reflection (Table 1). Upon achieving this state, participants described it as: "I was able to stay in my self-thoughts almost all the time. The inner talk was always present"; "I went through my life storytelling, I labelled all self-experiences and events" or "I called up my psychological self. I observed what kind of characteristics are related to it and used inner speech to help me. I named with internal speech different kinds of phenomena that rose up, like tension, tickling, mental images, feelings etc." (Table 2). During this state the phenomenological sense of "Self-concept clarity", "Reflection", "Thoughts continuity", and "Speed of thoughts" increased significantly, while the sense of "Effortlessness", "Selflocation", "Body perception", "Here \& now", as well as "Concatenation of thoughts" decreased significantly in comparison with the resting baseline state (Table 3). These observed dynamics of phenomenal features are not surprising given that the narrative/reflective self is extended in time (incorporates episodic and semantic autobiographical memory, as well as the expected or planned future) and relies heavily on language and cognitive agency (Neisser, 1988; Metzinger, 2003; Damasio, 2010; Perlovsky, 2011; Gallagher \& Zahavi, 2015; Musholt, 2015). This type of increased self-reflection and thinking about one's own narrative self presupposes increased sense of reflection and clearer self-concept expressed in better understanding of one's own states, traits and dispositions (Campbell et al., 1996; Snodgrass \& Thompson, 1997; Klein, 2010; Gallagher \& Zahavi, 2015). Since narratives normally involve a high level of cognition (Perlovsky, 2011; Hirsh et al., 2013), it is only natural that during the up-regulated I-state there was a significant increase in the speed of thoughts and their continuity.

These also may explain why the sense of "Here \& now" decreased during the up-regulation of the selfreflection and narration: the I-up state was associated with activation of autobiographical memories, comprising of episodic and semantic memories that consist of either concrete and specific items/episodes of personal information that are closely related to events situated in the past (Tulving, 2002; Piolino et al., 2009) or semantic personal information such as general knowledge of personal facts, but also general (repeated and extended) events (Tulving et al., 1988). Both of these require departure from the here and now to give rise to the sense of phenomenal recollection of previous personal events. Since, normally, here and now presuppose a self-location of the body perception (Windt, 2015; Metzinger, 2020) it is not surprising that expression of both of those phenomenological features decreased significantly during the I-up state (Table 3).

Experience of thinking about and reflecting upon oneself includes momentary narrative thoughts and inner speech, as well as reinterpretation of episodic and semantic memory events related to self (autobiographical story telling) (Neisser, 1988; Damasio, 1999, 2010; Gallagher, 2000; Gardiner, 2001; Demiray \& Bluck, 2011; Perlovsky, 2011; Gallagher \& Zahavi, 2015; Musholt, 2015; Klein, 2016), all of which are features related to the brain left SRN OM (Fig. 1; Fingelkurts \& Fingelkurts, 2017a,b, 2018). In this context, it is not surprising that the left SRN OM got increased functional integrity during up-regulation 
of the self-reflection/narration state (Fig. 3). This $I$-module includes a set of left posterior brain areas and systems involved in the expression of abovementioned subjective experiences (Frith, 1992; Gallagher, 2003a; D’Argembeau et al., 2005; Mar, 2004; Moriguchi et al., 2006; Brownsett \& Wise, 2010; Longe et al., 2010; Friston, 2011; Perlovsky, 2011; Moseley et al., 2013; Tops et al., 2014; Fingelkurts \& Fingelkurts, 2017a,b, 2018). The increased functional integrity of the left SRN OM (I-module) was markedly correlated with the feeling of increased self-reflection/narration indicated by the increased correlation between the values of I-module's integrity and expression of such phenomenological feature as "Self-concept clarity" and decreased expression of the sense of "Concatenation of thoughts" (see Table 5 and 6). While the former is simply natural, the later requires an additional note. One possible explanation is that during the up-regulation of the I-state participants did not employ a forced strategy of building a narrative, but rather allowed it to emerge naturally, which was reflected in decreased concatenation of thoughts: see for example a phenomenological report excerpt: "I called up my psychological self. I observed what kind of characteristics are related to it and used inner speech to help me. I named with internal speech different kinds of phenomena that rose up, like tension, tickling, mental images, feelings etc." (Table 2).

\subsection{Down-regulation of the reflective-narrative agency (I-down state)}

During I-down state participants were instructed to try to accept without judgment all experiences and to refrain from applying evaluative labels such as good/bad, right/wrong, or worthwhile/worthless and to allow self-reality to be as it is without any attempts to avoid, escape, or change it; to slow the train of thoughts. The vast majority of participants reported a very high rate of success in reaching and maintaining this state of decreased self-reflection (Table 1). Upon achieving this state, participants described it as: "My mind (mental self-reality) remained quite empty. I did not adhere/grip into the thoughts that every now and then emerged"; "Just noticed some fragments of thought, without a story or judging" or "Characteristic for the state was being present as an individual being, but the reactivity of the mind was missing, the inner commentator was quiet and the contents of experience could freely change and flow" (Table 2). During this state the phenomenological sense of "Involuntariness", "Rumination", "Here \& now", "The future", "The past" and "Thoughts continuity" decreased significantly in comparison with the resting baseline state (Table 3 ). These phenomenological observations pointed that participants in the I-down state did not experience themselves as being full-fledged thinking selves; disconnected thoughts just popped-up "in and out" in the absence of any explicit subjective sense of presence, past or future, thus indicating disruption in narration and self-reflection that together are a prerequisite for the cognitive self that persists across experiences ${ }^{11}$ (Metzinger, 2008, 2013; Sugimori et al., 2011). This conclusion is paralleled by a left hemisphere stroke case study where the

\footnotetext{
${ }^{11}$ Indeed, awareness that we are the same persons across time, also defined as temporally extended self-awareness, requires self-narration and autobiographical memory (Gallagher, 2000; Hohwy, 2007). Indeed, having access to autobiographical knowledge is fundamental for a cognitive Selfhood, because what actions one did in the past and the events one experienced define one's personal identity in the present and actually shapes how one imagines the self in the future (Morin, 2011).
} 
patient lost inner speech (Taylor, 2006). The phenomenological description of the patient suggested that loss of inner speech produced a general self-awareness deficit along with a number of more specific dysfunctions related to the patient's sense of individuality and autobiographical memories access (Morin, 2009). Interestingly, rumination which is a maladaptive form of self-reflection and which represents anxious attention directed to oneself (Trapnell, \& Campbell, 1999; Morin, 2011) also decreased significantly during I-down state in the present study, thus pointing to a potentially therapeutic value of achieving a controlled Idown state (using contemplative practices), especially for anxiety and depression (Vago \& Silbersweig, 2012; see for a review Fingelkurts et al., 2015).

The brain left SRN OM (I-module) has been implicated in the experience of thinking about and reflecting upon oneself, including momentary narrative thoughts, inner speech, and autobiographical material (Fig. 1; Fingelkurts \& Fingelkurts, 2017a,b, 2018). During the I-down state this I-module underwent a noticeable level of functional disintegration (Fig. 3), which is consistent with a reported decrease in selfreflection (Table 1). The decreased functional integrity of the left SRN OM (I-module) in relation to impaired self-reflection and narration was also documented in a separate independent study of a patient with extremely severe traumatic brain injury (Fingelkurts \& Fingelkurts, 2017b). Following this patient during 6 years after the injury has shown that the progressive recovery of the functional integrity of the brain Imodule was paralleled by the recovery of the patient's autobiographical memories, inner speech and the skill to plan for the future (Fingelkurts \& Fingelkurts, 2017b), thus providing additional empirical evidence for a causal relation between the brain left SRN OM (I-module) and self-reflection/narration.

At the same time, having a decreased or absent cognitive agency and autobiographical narrative does not necessarily presuppose, as correctly argued by Metzinger (2013), the decrease or absence of the phenomenological sense of being a self (in a narrow sense) as a phenomenal non-conceptual core in the act of knowing itself (Blanke \& Metzinger, 2009; Velmans, 2014). We will discuss this state of being a witnessing agent (self in the act of knowing) in the following two sections.

\subsection{Up-regulation of the witnessing observer (Self-up state)}

During Self-up state participants were instructed to focus on a nonsymbolic, non-linguistic sense of selfpresenting being; try to enhance the ability to merge into the self, which is a pure, self-referral consciousness, where self is only aware of self. Most participants reported a high rate of success in reaching and maintaining this state of increased witnessing agency (Table 1). Upon achieving this state, participants described it as: "During the witnessing state, the whole experience was mostly unified into a field of vivid experience arising and passing without creating attachment. It could be described as a kind of merging of senses and thoughts into soup of experience"; "Attention stayed quite well on the observing and observed self" or "The mind was alert and like a wide space. It was like a consciousness outside the individual limits or like an ocean of consciousness that connects me into the world" (Table 2). Furthermore, these phenomenological descriptions were in line with a number of concrete phenomenological aspects ("Self- 
concept clarity", "Observing", "Ownership", and "Here \& now") that increased significantly during this state when compared to baseline resting condition (Table 3). Thus, during Self-up state participants got significantly increased sense of being epistemic agents that possess increased self-concept clarity, established a self-representational kind of knowledge for the body, as well as epistemic self-control, all of which together are sufficient for creating a phenomenological first-person perspective (Metzinger, 2004, 2008, 2013; Revonsuo, 2006; Trehub, 2007; Blanke \& Metzinger, 2009; Hohwy, 2016). Further, as it has been discussed in detail by Metzinger (2004, 2008, 2013), this phenomenology also contributes to a sense that one has the capacity for selective, top-down attentional control, and also knows that it (oneself) possesses this capacity - thus having the phenomenal ownership (Gallagher, 2000; Zahavi, 2002; Metzinger, 2004, 2008; de Vignemont \& Fourneret, 2004; Hohwy, 2007, 2016). An increased sense of "Here \& now" during the Self-up state is compatible with up-regulated feeling of being a mere phenomenal spatio-temporal extensionless point ${ }^{12}$, that observes and witnesses itself and the world (Revonsuo, 2006; Trehub, 2007; Damasio, 2010; Velmans, 2014; Metzinger, 2020).

Since witnessing/observing agency (self in the act of knowing) relies on attention and non-reactive monitoring, when one feels directly and immediately present as the center of a phenomenal multimodal perceptual reality (the focus of one's phenomenal experience or a sensed "centre of gravity", Velmans, 2014), thus having the phenomenal first-person perspective (Metzinger, 2004, 2008; Revonsuo, 2006; Trehub, 2007; Blanke \& Metzinger, 2009) - features and functions related to a set of anterior brain areas (Fingelkurts \& Fingelkurts, 2011, 2018), it is not surprising that the functional integrity of the brain frontal SRN OM increased (Fig. 3) during up-regulation of the witnessing state. Such increased functional integrity of the frontal SRN OM (Self-module) was markedly correlated with the feeling of hyperwitnessing indicated by the increased positive correlation between the values of Self-module's integrity and expression of such phenomenological features as "Self-concept clarity", "Observing", "Ownership", and "Hear \& now" (see Table 5 and 6). This suggests that the sharper the subjective experience of being a witnessing agent (self in the act of knowing - an epistemic agent that is at the moment attempting to expand its knowledge by actively directing its own attention at oneself and the world; Metzinger, 2013; Velmans, 2014; see also Gallagher, 2000; Revonsuo, 2006; Zahavi, 2006; Damasio, 2010), the stronger the functional integrity within the brain Self-module (frontal SRN OM; Fig. 1). While the enhanced feeling of being a "witnessing observer" achieved by means of voluntary manipulation, like for example, as the result of meditation training (Fingelkurts et al., 2016b,c; Lutz et al., 2008; Kerr et al., 2011), is usually associated with improved wellbeing (Deikman, 1982; Vago \& Silbersweig, 2012), under certain conditions its spontaneous up-regulation

\footnotetext{
${ }^{12}$ While usually the spatiotemporal self-location is considered to be one of the most important ingredients for selfembodiment (Windt, 2015; Metzinger, 2020), neither the explicit body representation, nor bodily agency is necessary to experience oneself as a witnessing epistemic agent, because feeling as an extensionless point in space is sufficient for phenomenal self-identification (Metzinger, 2013). Indeed, such phenomenal feeling was often reported during various bodiless states (Kjellgren, et al., 2008; Berkovich-Ohana et al., 2013; Ataria et al., 2015; Windt, 2010; Wittmann, 2015).
} 
coupled with further alterations in other aspects of Selfhood may result in pathology ${ }^{13}$ such as depression (Fingelkurts \& Fingelkurts, 2017a), or post-traumatic stress disorder (Fingelkurts \& Fingelkurts, 2018).

The presence of a strong correlation between the values of brain Self-module's integrity and expression of phenomenological features related to a witnessing agency suggests that down-regulation of this agency should result in the corresponding disintegration of the integrity of the Self-module. We will discuss this Self-down state in the next section.

\subsection{Down-regulation of the witnessing observer (Self-down state)}

During Self-down state participants were instructed to try to achieve a feeling as in the contentless dream, though being awake, whereas one experiences a subjective loss of access to the conscious world as well as of the first-person perspective. Participants almost unanimously reported a medium-high rate of success in reaching and maintaining this state of decreased witnessing agency (Table 1). Upon achieving this state, participants described it as: "In that state my life history disappeared, just a vanishing hint about something that actually did not exist. I was not thinking or observing anything"; "It was a state that is difficult to describe. The amount of experience seemed minor and it is difficult to say where and to whom the experience happened or did it happen at all" or "Experience was empty, that is the best word to describe the state" (Table 2). Additionally, these phenomenological descriptions were congruent with the expression of a number of concrete phenomenological aspects ("Effortlessness", "Observing", "Ownership", and "Here \& now") that decreased significantly during this state in comparison with the baseline resting condition, as estimated by the set of standardised questionnaires (Table 3). The Self-down state is unique among all other states analysed in the present study, because it presupposes a strong diminishing or a complete absence (in the best case) of any form of phenomenal Selfhood, even the minimal form of spatial-temporal frame of reference - unextended point capable of epistemic self-control ${ }^{14}$, as well as absence of intentional content, complete emptiness, a void ${ }^{15}$ (Windt, 2015; Metzinger, 2020). Thus, it is not surprising that the phenomenal

\footnotetext{
${ }^{13}$ Even though, the exact mechanism that could explain why such maladaptive processes take place is mostly unclear, one can speculate that for the up-regulated sense of witnessing to be accompanied by subsequent negative mood or anxiousness some other factors and conditions must be taken into play (Fingelkurts \& Fingelkurts, 2017a, 2018). More specifically, up-regulation of the Self-module of the brain SRN may lead to enhancement of both metacognition and meta-awareness. Studies have shown that if metacognitive processes are activated (that include rumination) during high vigilance states (that include bodily tension and inability to relax) without meta-awareness, they give rise to negative or depressed mood (Gruberger et al., 2013; Deng et al., 2014). However, if enhanced meta-awareness does not accompanied by the activation of the metacognitive processes, the negative mood does not arise (Konjedi \& Maleeh, 2017). This is exactly what happens as a result of meditation training - maintenance of a nonreactive meta-awareness (either wide as in mindfulness or narrow as in focused attention) to what is being experienced (Braboszcz et al., 2010), by only observing the content of awareness without any interpretation or judgment even if the content is negative (Konjedi \& Maleeh, 2017).

${ }^{14}$ As it has been argued in detail by Metzinger $(2013,2020)$, the feeling of being an extensionless point in space is sufficient for phenomenal self-identification that is tied to an individual phenomenal first-person perspective.

${ }^{15}$ In the Eastern contemplative tradition such a state is traditionally termed as "pure consciousness" or "witness consciousness" and referred to a wakeful but contentless (nonintentional) experience (Forman, 1998; Shear, 2007), not tied to an individual first-person perspective and thus characterized neither by a centre nor periphery (Metzinger, 2020), and which cannot be introspectively individuated to create indivisible units of experience - therefore, frequently
} 
sense of observing, ownership and here-\&-now decreased during this state leading to a lack of subjective experience of oneself as located at a point (or a region) in a spatial frame of reference, as well as lack of orientation in time (so-called temporal self-location ${ }^{16}$; Wittmann, 2015, see also Windt, 2015). All of this leads to the defining characteristic of Self-down state which is a lack of individual phenomenal first-person perspective (Metzinger, 2013, 2020; Millière, 2020). A decreased sense of observing and ownership lays a foundation for the feeling of low complexity of such a state which is characterised by a lack of intentional content and narrative. Usually, this state is difficult to achieve and maintain (as is also documented by the phenomenological reports of the study participants; see Table 2), so this requires a constant effort and may explain why the sense of effortlessness decreased during reaching selfless state. Indeed, as it has been discussed by philosophers (Millière \& Metzinger, 2020; Metzinger, 2020), the sense of effort might be enough to sustain some level of subjectivity encompassing the phenomenal quality of attentional agency, thereby establishing a self-representational kind of knowledge for the organism (Metzinger, 2013).

In theory, it could be suggested, if a complete selfless state is achieved, then there will be no any phenomenal experience of being a self as a separate entity having the experience (Windt, 2015) and thus there will not be any experience of effort either. In our study, during the down-regulation of Self-state, the functional integrity of the brain frontal SRN OM significantly decreased (Fig. 3). This decrease was paralleled by a fading feeling of hypowitnessing indicated by the marked positive correlation between the low values of Self-module's integrity and decreased expression of such phenomenological features as "Observing", "Ownership", "Hear \& now" and also "Effortlessness" (see Table 5 and 6). This positive correlation between neurodynamics of the frontal SRN OM (Self-module) and phenomenal features suggests that if participants would manage (which they did not, see Table 1) to achieve a complete selfless state, when even the bodiless focus of one's minimal phenomenal experience as a sensed "centre of gravity" (Velmans, 2014; see also Metzinger, 2004, 2008; Revonsuo, 2006; Trehub, 2007; Blanke \& Metzinger, 2009) would fade away, the frontal SRN OM would undergo complete functionally disintegration, similar to what happens in patients who are in a confirmed vegetative state ${ }^{17}$ (Fingelkurts et al., 2012). In this extreme state, the viewpoint of the observing self is vanished, one would experience a subjective loss of access to the conscious world. Following Baars et al. (2003) such a state "[...] might not necessarily block the objects of consciousness; rather, the observing subject might not be at home" (p. 674). Indeed, the raw sensory stimuli, that originate from both the outside and within the organism, do appear during these states, but they are not integrated in the context of a first-person meaningful narrative (Fingelkurts et al., 2012).

conceptualized as "non-duality" and "non-oneness" (Chatterjee, 1982; Fort, 1984; Gupta, 1998; Fasching, 2010; Josipovic, 2014). A similar form of phenomenal experience could be also spontaneously achieved during dreamless sleep (Windt, 2010, 2014, 2015; Thompson, 2015), under psychedelics or as a result of complete sensory/perceptual deprivation (for a review see Millière, 2020).

16 This is also compatible with the model of "temporal thinness" developed by Friston (2018) as it corresponds to a breakdown of the normal feeling that one is present in a temporal order, because only a very short timescale is preserved that could not support complex state transitions or sequences over time (Friston et al., 2017; Friston, 2018).

${ }^{17}$ Interestingly, the level of preserved functional connectivity in this anterior module of these patients is predictive of the subsequent recovery of self-consciousness after six years of unconsciousness (Fingelkurts et al., 2016a). 


\subsection{Interaction between the aspects of Selfhood}

From the above discussion of the six target states ("Me" $\uparrow \downarrow$, “I” $\uparrow \downarrow$, and "Self" $\uparrow \downarrow$ ) it has become apparent that when any given isolated aspect/feature of Selfhood was either up- or down-regulated, there were also some alterations (usually congruent) in the non-target features. Since it was established that the expression of phenomenal features was strongly correlated with the strength of functional integrity within the corresponding SRN OMs (Table 5 and 6), it was particularly interesting to see how the strength of functional integrity of the non-target OMs changed when participants either up- or down-regulate the target aspects/features of Selfhood. As Figure 4 shows, there were (small) modulations in the strength of functional integrity of the non-target OMs that systematically (though non-significantly) follow the direction of the upor down-regulation of the target OMs. The only exception was a decrease of functional integrity within the left posterior OM (non-target OM) during the up-regulation of Self-state marked by the significant increase in the frontal $\mathrm{OM}$ (target $\mathrm{OM}$ ) functional integrity (Fig. 4). This last relation is not surprising since participants were instructed, while up-regulating the Self-state, to try to focus on a nonsymbolic and nonlinguistic sense of self-presenting being. In this context, the result just confirms that participants were able to successfully follow experimental instructions.

On a more theoretical perspective, these observations, coupled with related phenomenological descriptions (Table 2, 3; see also Blakemore et al., 2000; Parnas \& Handest, 2003; Millière, 2017, 2020; Ataria et al., 2015; Pollan, 2018), provide additional support to a pattern theory of self (Gallagher, 2013), which predicts that interventions that target one aspect or component of complex Selfhood, may lead via dynamical interrelation to some changes in other different aspects/features/components of self and, further, supports the conclusion that various features of Selfhood are not simply an additive list of features, but rather a set of components dynamically interrelated in a pattern forming a complex emergent gestalt - Selfhood (Gallagher \& Daly, 2018). On a neurophysiological level, these observations highlight that the respective networks (OMs) that support different phenomenological features of Selfhood are hierarchically related (Fingelkurts \& Fingelkurts, 2011), which is in agreement with the well-established anatomical and functional interrelations in the brain (Vvedensky, 1906; Livanov, 1977; Friston, 1994; Bressler, 1995; Fingelkurts et al., 2005; Mišić et al., 2016). While the precise nature of these dynamic interrelations is yet to be explored in an specifically designed experiments (what was not the aim of the current study), the limited results of this study allow us to speculate that the complex Selfhood, described in terms of brain SRN dynamics and related phenomenological descriptions, is not a fixed entity "living" on its own, but rather an ongoing emergent property generated by the dynamic interrelation of at least three brain SRN modules that support three phenomenological features (witnessing, self-reflection, and self-embodiment) of Selfhood, which are themselves also complex elements having their own composition. It seems that such a neurophysiological three-dimensional construct model of the complex experiential Selfhood matches well with phenomenological (as well psychological and also conceptual) distinctions between different aspects of self 
and treats them as commensurate to one another and not as opposites (see also Gallagher, 2013; Gallagher \& Daly, 2018). Thus, one may consecutively consider this triad model (as described above) to be more empirically plausible with regard to a complex Selfhood than those models that instead treat the self as a homogenous and fixed entity.

\section{Summary comments and an integrative model}

The results of the present study (Fig. 3, Table 2, 3, 5 and 6), when considered together, clearly point to a tight (causal) relations between the three brain SRN modules (frontal OM, right posterior OM, and left posterior OM) and correspondent to them three phenomenological features of Selfhood ("Self" - witnessing agency, "Me" - body representational-emotional agency, and "I" - reflective/narrative agency). Based on the analysis of these results, combined with empirical findings on the dynamics of the triad of SRN modules in different brain and mind pathologies, such as disorders of consciousness (minimally conscious vs vegetative states; Fingelkurts et al., 2012, 2016a), brain damage (Fingelkurts \& Fingelkurts, 2017b; Kullberg-Turtiainen et al., 2019), depression (Fingelkurts \& Fingelkurts, 2017a), and post-traumatic stress disorder (Fingelkurts \& Fingelkurts, 2018), as well as considering the modulation of Self-Me-I modules as a function of meditation (Fingelkurts et al., 2016b,c) and the available literature on the Selfhood, we would like to propose a dynamic, functional model of relations between the three SRN OMs and experiential Selfhood.

As a first approximation within the present theoretical framework, the following speculative picture seems to emerge: An important starting point for understanding of complex experiential Selfhood is a simplest, primordial or minimal aspect of self-consciousness which is pre-reflective, non-conceptual, prelinguistic, immediate and emerges in a bottom-up fashion - embodiment (Gallagher, 2000, 2005; Legrand, 2006; Lenggenhager et al., 2007; Metzinger, 2008). It is a background feeling that a present action or movement is performed by me, and that a present perceptual experience is had by me (Zahavi, 2006; Hohwy, 2007). "Me" here represents the spatiotemporal frame of reference ${ }^{18}$ centred geometrically on the body and existing in the specious present (Hohwy, 2007). The functional property of centeredness leads to the geometrical property of perspectivalness (Blanke \& Metzinger, 2009). According to Metzinger $(2004,2008)$, embodiment is a very special aspect of Selfhood in a sense that it is the only representational structure that emerged and continues to exist as a result of the constant generation and receiving the internal input via different intero- and proprioceptive stimuli, so-called constant background "buzz" of somatosensory input in the brain (Kinsbourne, 1995; for an extensive theoretical treatment of the subject, see also Damasio, 1999; Hohwy, 2010; Seth et al., 2012; Apps \& Tsakiris, 2014). In other words, embodiment is neurobiologically anchored (Metzinger, 2008) through a specifically dedicated and integrative brain functional module (right

\footnotetext{
${ }^{18}$ In this account, "mineness" as an implicit sense of ownership is always situated in the spatiotemporal reference frame (Metzinger, 2004; Zahavi, 2005), where it introduces the temporal feeling of "being already familiar" with the input (Hohwy, 2007; Limanowski \& Blankenburg, 2013). This idea that the living body is experienced as mine (as owned) can be traced back to early phenomenologists like Merleau-Ponty or Husserl (see Gallagher, 1986).
} 
posterior SRN OM${ }^{19}$, Fingelkurts et al., 2012, 2016a,b,c, Fingelkurts \& Fingelkurts, 2017a,b, 2018). The proper functional integrity of this right posterior SRN OM (which is responsible for the basic, primordial aspect of self with a geometrical first-person perspective) enables a crucial precondition for the expression of other aspects of Selfhood (such as witnessing agency, and self-reflection), supported by their corresponding SRN OMs (Fig. 5; arrow 1).

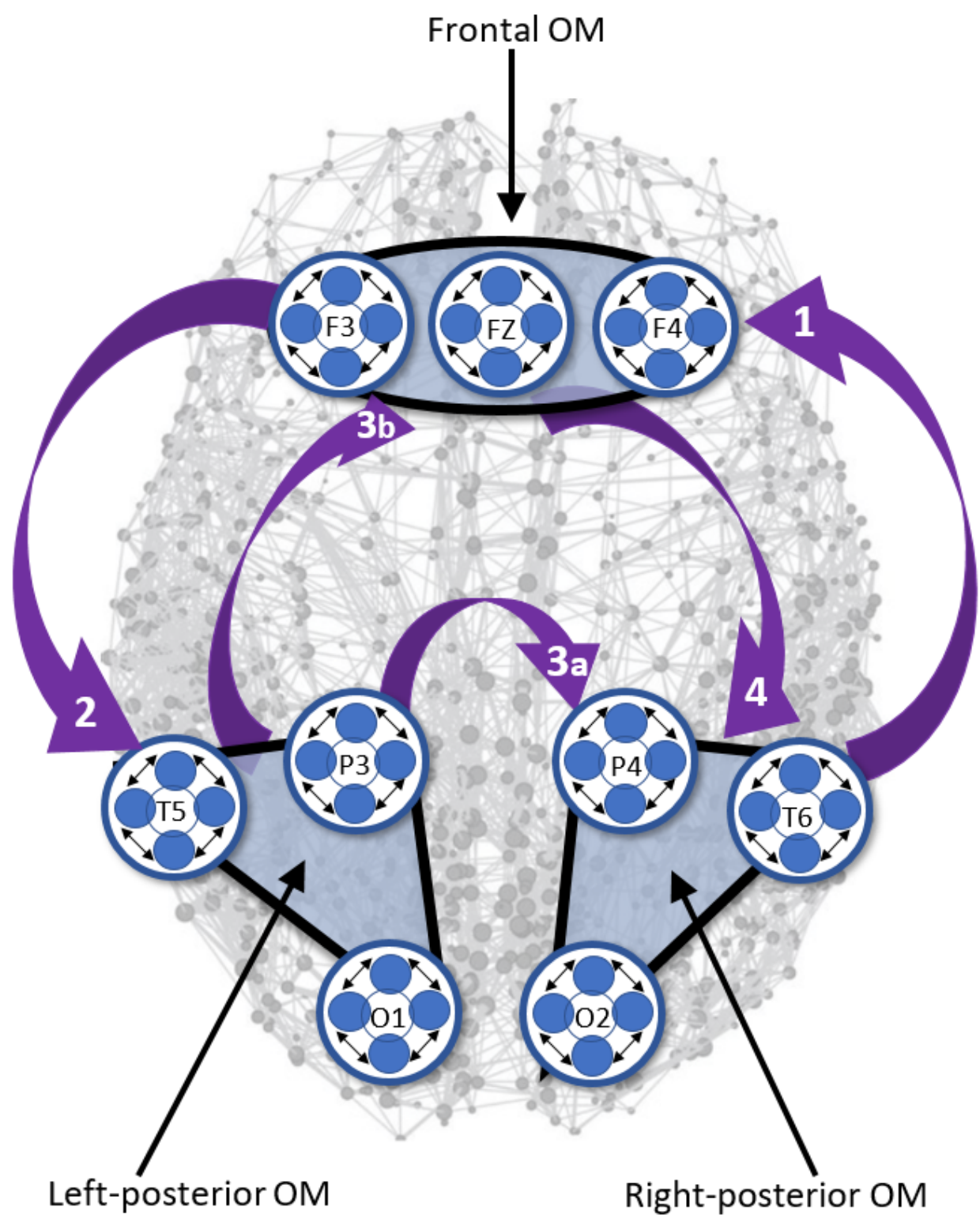

Figure 5. Schematic illustration of the putative dynamic relations between the three operational modules (subnets) of the self-referential brain network. The legend of this figure is the same as that of the Figure 1. Explanations of the numbered arrows are provided in Section 5.

\footnotetext{
${ }^{19}$ Interestingly, it is the right parietal brain regions that show the fastest maturation (including interconnectivity) from 1 month up to the age of three years (Hashimoto et al., 1995; see also Yakovlev \& Lecours, 1967), thus supporting the conceptualization that the neurophysiological substratum (in the form of an integrated right SRN OM) for the prereflective embodiment is readily available already in the infantry.
} 
The anterior SRN OM, by integrating information (coming from the right posterior SRN OM) about the pre-reflective background sense of mineness and geometrical perspectivalness with attentional effort and executive control which it supports, creates the phenomenal point of view (phenomenal first-person perspective; Metzinger, 2004, 2008; Revonsuo, 2006; Trehub, 2007; Blanke \& Metzinger, 2009) and the sense of agency (Fig. 5). In this conceptualisation, it is a phenomenal non-conceptual core in the act of knowing itself (Blanke \& Metzinger, 2009; Velmans, 2014), that is experienced as a directly and immediately present centre of a phenomenal multimodal perceptual reality (the focus of one's phenomenal experience, so called sensed "centre of gravity", Velmans, 2014). As it is correctly pointed by Blanke and Metzinger (2009), the fact that a system represents itself not only as a core/centre but also as a holistic entity in the act of knowing, is exactly what makes consciousness subjective ${ }^{20}$. However, at this stage of the dynamic loop that creates Selfhood, the phenomenal agent does not yet possess the concept of being a subject of experience which is normally expressed linguistically through $I$-thoughts, as for example, "I myself owning my body" or "I myself am a subject of this experience", or "I myself am a thinking thing" 21. In such a narrow sense of self, the agent is a passive observer, who just witnesses events, perceptions, or thoughts in its implicit first-person mode of givenness (Fingelkurts et al., 2016b). Therefore, normally functioning integrity of the anterior SRN OM enables a precondition for genuinely reflexive, conceptual aspect of Selfhood pattern - an explicit sense of "I" through self-reflection and narration" ${ }^{22}$ (Fig. 5; arrow 2).

The left posterior SRN OM is the seat of such self-reflection and narration (Fingelkurts et al., 2012, 2016a,b,c, Fingelkurts \& Fingelkurts, 2017a,b, 2018) which allows oneself to think of one's perspective as one's own, as well as to have a concept of others as having subjective points of view which are different from one's own (Baker, 2000; Praetorius, 2009). According to Strawson (1997), this happens in childhood around the language acquisition period, when children get the realisation "of the fact that one's thoughts are unobservable by others, the experience of the profound sense in which one is alone in one's head - these are among the very deepest facts about the character of human life, and found the sense of the mental self" (p. 407). One can now think the I-thoughts as " $I$ am aware of a specific object $m e$ ", thus self-reflectively

${ }^{20}$ Curiously, such a phenomenal property may be rather exceptional in the animal kingdom, if one considers the findings that the anterior brain areas contain a very unique type of neurons - so called von Economo neurons, that has been localized and described in detail by von Economo (von Economo \& Koskinas, 1925; von Economo, 1926). Comparative studies have shown that these neurons exist only among great apes and especially abundant in humans (Nimchinsky et al., 1999; Allman et al., 2010). Based on further findings that degeneration of von Economo neurons in patients with fronto-temporal dementia is associated with an observable loss of self-conscious behavior (Seeley et al., 2006), it was proposed that these neurons may have a special role in the conscious experience of Selfhood (Allman et al., 2010).

${ }^{21}$ However, one may expect the existence of a thin sense of epistemicity at this stage. Epistemicity refers to "the mere phenomenal signature of knowing, i.e., a functionally autonomous experience of subjective confidence or certitude, a representation of model evidence as such. [It] could then be the special phenomenal character of non-directed, nonagentive and aperspectival "knowingness" (Metzinger, 2020; p. 28).

${ }_{22}$ Interestingly, the ability of attention (supported by anterior brain areas) to affect (through a top-down control mechanism or predictions) the integration of the activities related to the body, including interoceptive and exteroceptive signals has been clearly documented (Craig, 2010; Seth, 2013; Seth \& Critchley, 2013; Fingelkurts \& Fingelkurts, 2015b). In this context, the anterior SRN OM may impose a priming effect on the embodiment aspects of Selfhood (Fig.5; arrow 4). 
identifying specific properties of it, like "I" am localised within this mine bodily volume, which has particular shape and size (Legrand, 2007). Proper functional integration of the left OM now makes it possible to engage in autobiographical thoughts involving semantic and episodic memory events related to self, as well as projecting the self into the future, thus enabling the sense of invariance of a narrative self over time (James, 1890; Neisser, 1988; Damasio, 1999, 2010; Gallagher, 2000; Demiray \& Bluck, 2011; Metzinger, 2003; Klein, 2016; Friston et al., 2017). In this way, the left posterior SRN OM enables explicit selfreflection on the embodiment and mineness (Fig. 5; arrow 3a) and also provides strong epistemic input, flavoured by the conceptual and linguistic aspects ${ }^{23}$, to the anterior SRN OM, thus reinforcing the phenomenal self with conceptual epistemicity (Fig. 5; arrow 3b). This conceptualisation pointes to the importance of narration as "a means of retrieving, disclosing, temporally mapping, and connecting all the other aspects" (Gallagher \& Daly, 2018; p. 5) of the complex Selfhood gestalt pattern for human selfconsciousness (see also Frith \& Metzinger, 2016).

Now, that the dynamic loop of the interactions among characteristic aspects (indexed by brain SRN modules) of Selfhood is closed (Fig. 5; arrows 1-4), full-blown complex Selfhood emerges as a locus of experience and self-ascription ${ }^{24}$ with a strong first-person perspective and bodily agency, accompanied by the attentional and cognitive control at the mental level, coupled with a sense of "knowing that one knows", and revealed through the extended autobiographical self-narrative model equipped with social, emotional and evaluational aspects of self-experience. However, since complex Selfhood is a dynamic pattern, where different features or aspects may have different weights and configuration of the relations (with constant dynamic readjustments), the coherent sense of Selfhood can be diminished or enhanced and may also acquire some particular nuanced qualitative flavour (Gallagher \& Daly, 2018).

Finally, at this point of the analysis, we are ready to answer the question of whether there is any individual aspect among the triad aspects of the complex Selfhood, which may be necessary (in an essentialist sense; see Gallagher, 2013) ingredient to constitute a self? Meaning, that phenomenal self cannot, even in principle, exist without this particular feature that makes up the constitutive basis of Selfhood. Considering the neurophenomenological results of the present study and also the results of the Self-, Me-, and I-module dynamics in patients with disorders of consciousness (Fingelkurts et al., 2012, 2016a) and brain damage (Fingelkurts \& Fingelkurts, 2017b), it is now plausible to draw a following putative conclusion: the "Self" OM (anterior subnet of the SRN) may have a central role among the three OMs in granting a critical quality for the sense of self - the phenomenal non-conceptual core in the act of knowing

\footnotetext{
${ }^{23}$ According to Perlovsky (2011), language and related semantics guide the development of internal cognitive models using narrative that is also influenced by the culture and collective wisdom that have accumulated in language (Hirsh et al., 2013). Therefore, in the autobiographical narrative there is a reflection of how we make sense of ourselves in a social environment (Limanowski \& Blankenburg, 2013) for which a distinction between actions and states of the self and those of others, as well as attempting to see myself as others see me, are crucially important (Farmer \& Tsakiris, 2012; Gallagher \& Zahavi, 2015).

${ }^{24}$ In thermodynamic terms, it could be conceptualized as an order parameter. The notion of "order parameter" refers to the parameter that determines (or enslaves) the behavior of individual parts/components of a system (Haken, 1977, 2004; Freeman \& Vitiello, 2006). For further reading on thermodynamics of self, see Yufik, 2013 and Friston, 2018.
} 
itself (Blanke \& Metzinger, 2009; Velmans, 2014) within the whole spectrum of human behaviours and activities (see also Fingelkurts \& Fingelkurts, 2011 and further Araujo et al., 2015; Frewen et al., 2020). "It is the foundation upon which our 'autobiographical', 'narrative' and 'social' selves (represented by both posterior OMs) are built" (Fingelkurts et al., 2016a; p. 47).

Indeed, as we have seen, a significant decrease or even complete loss of embodiment and bodily originated geometrical perspectivalness (indexed by the right posterior SRN OM) or narrative and conceptual self-reflection (indexed by the left posterior SRN OM) did not result in the disappearance of the most fundamental kind of phenomenal experience of being someone - a witnessing observer. Only the significant decrease or a full loss of the phenomenal sense of witnessing (together with attentional control) when even minimal phenomenal self as the abstract unextended point in space is vanished, mediated by a significant functional disintegration of the anterior SRN OM, was associated with significant decrease or complete absence of intentional content, phenomenal spatiotemporal self-location and first-person perspective, as well a general ability to introspectively create indivisible units of experience (not even a single one), thus leading to a suspension of the subject's inner narrative life (Fingelkurts et al., 2012, 2016a). In other words, and paraphrasing Baars et al. (2003) in such a situation, the lights are on but observing subject is not at home. So, it seems that proper functional integrity of the anterior SRN OM is necessary and sufficient ${ }^{25}$ condition to support the basic structural feature of complex Selfhood that guarantees that one experiences oneself as a distinct epistemic entity located at the centre of the phenomenal world one is witnessing and observing.

The final note has to be made here. We are not claiming that the discussed three-dimensional construct model for the complex experiential Selfhood - in its present form - is the final word on self-consciousness or gives answers to all relevant questions. Neither do we argue that the three aspects of Selfhood that are taken as a building blocks of the present model exhaust the whole set of phenomenal features (see for example Gallagher \& Daly, 2018). However, there could be a useful way in which extra features may be grouped within essentially three dimensions that are considered in our triad model of Selfhood. We regard our model as a starting point which is open to further conceptual development, refinement, and constructive criticism. By the same token, already in the present form, this triad model of Selfhood is fairly comprehensive, and can be used as a practical "tool" that allows neurophysiological study the triad of separate, though closely related qualities which together form a unified sense of Selfhood.

\footnotetext{
${ }^{25}$ To avoid a possible misunderstanding, we would like to stress that this is not to say that the other two SRN modules that support embodiment (right posterior SRN OM) and self-reflected narration (left posterior SRN OM) are not important. However, their importance is mostly etiological. Etiological explanation considers the causal history or pathway chain of events (Craver, 2001) that either brought about or modulated a given phenomenon (in the present context, Selfhood) and it is neutral about the constitutive entities (see Fig. 1 in Fingelkurts et al., 2013), because causal dependence does not entail ontological dependence (Revonsuo, 2006). However, when the complex Selfhood is formed and in place, "it can in principle exist even in the absence of the entities and activities that make up its etiological pathway, while it cannot, even in principle, exist without the entities and activities that make up its constitutive basis" (Revonsuo, 2006; p. 22)
} 


\subsection{Limitations}

The study has several limitations that have to be kept in mind while considering the results. First, the study sample size was by necessity small as it was restricted to participants with a history of long-term meditation practice. Despite the small sample size, the main effects of the study were quite stable across participants as indicated by the coefficient of variability of the group results (see Table 4). Further, it remains to be seen whether the findings of the present study would generalize to untrained (a meditation naïve) general population. Therefore, the results of this study should be validated in a study with a larger and more representative samples size. Second, there is some concern (see for example, Davidson, 2010) on whether the study participants can reliably report on the quality and/or phenomenology of their subjective experiences. While this can be a problem for the general population, long-term meditators (who were the participants of the present study) usually possess an enhanced ability to reflect upon and report their subjective experiences with a high degree of accuracy (Lutz et al., 2007; Berkovich-Ohana et al. 2013; Dor-Ziderman et al. 2013). Third, the present study was limited only to an EEG alpha range analysis. While we have provided an extensive justification why the alpha range was chosen among other EEG frequency ranges (see section "EEG registration and pre-processing"), other frequencies may reveal different results.

Despite these limitations, the results presented here are novel and provide a rich framework for new studies. The major strengths of the current study included (i) hypothesis-driven analysis that was derived from the neurophysiological triad model of Selfhood and examined how the functional connectivity within the three specific SRN OMs relates to three aspects of Selfhood, (ii) state-of-the-art EEG analysis that includes operational synchrony measure, that is specifically tuned to extract from the EEG the so-called operational modules that are the sets of synchronized operations produced by distant neuronal assemblies in the brain (Fingelkurts \& Fingelkurts, 2001, 2008, 2015a); this is in agreement with the work of Freeman and Kozma (Freeman \& Kozma, 2000; Kozma \& Freeman, 2009; Freeman et al., 2015) regarding the emergent spatio-temporal activity patterns in the brain as windows on cognitive functions and consciousness, and (iii) adoption of the neurophenomenological design (Gallagher, 2003b; Lutz \& Thompson, 2003; Fazelpour \& Thompson, 2015) enabling us to integrate both a first-person phenomenological and a third-person neurophysiological perspectives within the same study framework.

A unique aspect of the current research is that it utilized a hybrid approach that combined resting-state and task-based paradigms. The "targeted states" that the participants were required to attain are actually tasks that they must accomplish. To have participants accomplish these tasks in a resting-state framework (no stimuli were presented and no motor responses were required) is an elegant way to study different aspects of mentation as a function of the brain SRN OMs functional integrity. Further, to the best of our knowledge, this is the first study that besides the down-regulation of different phenomenological features of Selfhood also investigated their up-regulation. 


\section{Author contributions}

Andrew A. Fingelkurts: Conceptualization, Methodology, Investigation, Resources, Data curation, Formal analysis, Writing - Original Draft, Visualization, Project administration. Alexander A. Fingelkurts: Conceptualization, Methodology, Investigation, Resources, Formal analysis, Writing - Review \& Editing, Visualization. Tarja Kallio-Tamminen: Conceptualization, Methodology, Writing - Review \& Editing, Funding acquisition.

\section{Acknowledgements}

The authors thank the participants of this study for dedicating their time and expertise, and for their interest in advancing the scientific understanding of experiential Selfhood. The authors would like further to thank C. Neves (Computer Science specialist) for programming, technical, and IT support and D. Skarin for English editing.

\section{Declaration of Conflicting Interests}

None of the authors have potential conflicts of interest with respect to the research, authorship, and/or publication of this article to be disclosed.

\section{Funding}

The authors received no funding for the research; however, some limited financial support was provided by private donations. These private persons had no role in the study design, data collection and analysis, decision to publish or preparation of the manuscript.

\section{References}

Allman, J. M., Tetreault, N. A., Hakeem, A. Y., Manaye, K. F., Semendeferi, K., Erwin, J. M., ... Hof, P. R. (2010): The von Economo neurons in frontoinsular and anterior cingulate cortex in great apes and humans. Brain Structure and Function, 214(5-6), 495-517.

Allport, G. W. (1961). Patterns and growth in personality. New York: Holt, Rinehart \& Winston.

Andrews-Hanna, J. R. (2012). The brain's default network and its adaptive role in internal mentation. Neuroscientist, 18, 251-270.

Andrews-Hanna, J. R., Smallwood, J., Spreng, R. N. (2014). The default network and self-generated thought: component processes, dynamic control, and clinical relevance. Annals of the New York Academy of Sciences, 1316, 29-52.

Andrews-Hanna, J. R., Reidler, J. S., Sepulcre, J., Poulin, R., \& Buckner, R. L. (2010). Functional-anatomic fractionation of the brain's default network. Neuron, 65, 550-562.

Apps, M. A., \& Tsakiris, M. (2014). The free-energy self: a predictive coding account of self-recognition. Neuroscience and Biobehavioral Reviews, 41, 85-97. 
Araujo, H. F., Kaplan, J., Damasio, H., \& Damasio, A. (2015). Neural correlates of different self domains. Brain and Behavior, 5, e00409. doi:10.1002/brb3.409

Arzy, S., Thut, G., Mohr, C., Michel, C. M., \& Blanke, O. (2006). Neural basis of embodiment: distinct contributions of temporoparietal junction and extrastriate body area. The Journal of Neuroscience, 26, 8074-8081.

Asai, T., Mao, Z., Sugimori, E., \& Tanno, Y. (2011). Rubber hand illusion, empathy and schizotypal experiences in terms of self-other representations. Consciousness and Cognition, 20, 1744-1750.

Asendorf, J. B. (2002). Self-awareness, other-awareness, and secondary representation. In A. Meltzoff, \& W. Prinz (Eds.), The imitative mind: Development, evolution, and brain bases (pp. 63-73). Cambridge, England: Cambridge University Press.

Aspell, J. E., Lenggenhager, B., \& Blanke, O. (2009). Keeping in touch with one's self: multisensory mechanisms of self-consciousness. PLoS One, 4, e6488. doi:10.1371/journal.pone.0006488

Astafiev, S. V., Stanley, C. M., Shulman, G. L., \& Corbetta, M. (2004). Extrastriate body area in human occipital cortex responds to the performance of motor actions. Nature Neuroscience, 7(5), 542-548.

Ataria, Y. (2014). Traumatic memories as black holes: A qualitative-phenomenological approach. Qualitative Psychology, 1, 123-140.

Ataria, Y., Dor-Ziderman, Y., \& Berkovich-Ohana, A. (2015). How does it feel to lack a sense of boundaries? A case study of a long-term mindfulness meditator. Consciousness and Cognition, 37, 133147.

Austin, J. H. (2000). Consciousness evolves when the self dissolves. Journal of Consciousness Studies, 7 , 209-230.

Aymerich-Franch, L., Petit, D., Ganesh, G., \& Kheddar, A. (2015, 30 June-2 July). Embodiment of a humanoid robot is preserved during partial and delayed control. Proceedings of the IEEE International Workshop on Advanced Robotics and its Social Impacts (ARSO 2015), Lyon, France. doi: 10.1109/ARSO.2015.7428218

Baars, B. J., Ramsøy, T. Z., \& Laureys, S. (2003). Brain, conscious experience and the observing self. Trends in Neurosciences, 26(12), 671-675.

Baer, R. A., Smith, G. T., Hopkins, J., Krietemeyer, J., \& Toney, L. (2006). Using self-report assessment methods to explore facets of mindfulness. Assessment, 13, 7-45.

Baker, L. R. (2000). Persons and bodies. A constitution view. Cambridge England: Cambridge University Press.

Barrett, L. F., Mesquita, B., Ochsner, K. N., \& Gross, J. J. (2007). The experience of emotion. Annual Review of Psychology, 58, 373-403.

Basar, E., \& Guntekin, B. (2009). Darwin's evolution theory, brain oscillations, and complex brain function in a new "Cartesian view". International Journal of Psychophysiology, 71, 2-8.

Beck, A. T. (1987). Cognitive models of depression. Journal of Cognitive Psychotherapy, 1, 5-37.

Beck, A. T., Epstein, N., Brown, G., \& Steer, R. A. (1988). An inventory for measuring clinical anxiety: Psychometric properties. Journal of Consulting and Clinical Psychology, 56, 893-897.

Beck, A. T., Ward, C. H., Mendelson, M., Mock, J., \& Erbaugh, J. (1961). An inventory for measuring depression. Archives of General Psychiatry, 4(6), 561-571.

Benninger, C., Matthis, P., \& Scheffner, D. (1984). EEG development of healthy boys and girls. Results of a longitudinal study. Electroencephalography and Clinical Neurophysiology, 57, 1-12.

Berkovich-Ohana, A., Dor-Ziderman, Y., Glicksohn, J., \& Goldstein, A. (2013). Alterations in the sense of time, space and body in the Mindfulness-trained brain: a neurophenomenologically-guided MEG study. Frontiers in Psychology, 4, 912. doi:10.3389/fpsyg.2013.00912

Berlucchi, G., \& Aglioti, S. (1997). The body in the brain: neural bases of corporeal awareness. Trends in Neurosciences, 20, 560-564.

Bermúdez, J. L. (1998). The paradox of self-consciousness. Cambridge, MA: MIT Press.

Bermúdez, J. L. (2001). The sources of self-consciousness. Proceedings of the Aristotelian Society, 102(1), $87-107$.

Bermúdez, J. L., Marcel, A. J., \& Eilan, N. (Eds.). (1998). The Body and the Self. Cambridge: MIT Press.

Bitbol, M., \& Gallagher, S. (2018). The free energy principle and autopoiesis. Comment on "Answering Schrödinger's question: a free-energy formulation" by Maxwell James Désormeau Ramstead, Paul Benjamin Badcock, Karl John Friston. Physics of Life Reviews, 24, 24-26. 
Blackmore, S. (2015, June). Out-of-body experiences, and what they tell us about our selves. Toward a Science of Consciousness 2015. In Book of Abstracts (p. 97). University of Helsinki, Finland.

Blakemore, S. J., Smith, J., Steel, R., Johnstone, E. C., \& Frith, C. D. (2000). The perception of self-produced sensory stimuli in patients with auditory hallucinations and passivity experiences: evidence for a breakdown in self-monitoring. Psychological Medicine, 30, 11311139.

Blanke, O. (2012). Multisensory brain mechanisms of bodily self-consciousness. Nature Reviews Neuroscience, 13, 556-571.

Blanke, O., \& Mohr, C. (2005). Out-of-body experience, heautoscopy, and autoscopic hallucination of neurological origin Implications for neurocognitive mechanisms of corporeal awareness and self-consciousness. Brain Research Brain Research Reviews, 50, 184-199.

Blanke, O., \& Metzinger, T. (2009). Full-body illusions and minimal phenomenal selfhood. Trends in Cognitive Sciences, 13, 7-13.

Blanke, O., Ortigue, S., Landis, T., \& Seeck, M. (2002). Stimulating illusory own-body perceptions. Nature, 419, 269-270.

Boly, M., Tshibanda, L., Vanhaudenhuyse, A., Noirhomme, Q., Schnakers, C., Ledoux, D., ... Laureys, S. (2009). Functional connectivity in the default network during resting state is preserved in a vegetative but not in a brain dead patient. Human Brain Mapping, 30, 23932400.

Braboszcz, C., Hahusseau, S., \& Delorme, A. (2010). Meditation and neuroscience: From basic research to clinical practice. In R. Carlsted (Ed.), Integrative clinical psychology, psychiatry and behavioral medicine: Perspectives, practices and research (pp. 755-778). New York, NY: Springer.

Bressler, S. L. (1995). Large-scale cortical networks and cognition. Brain Research Reviews, 20, 288-304.

Brewer, J. A., Worhunsky, P. D., Gray, J. R., Tang, Y.-Y., Weber, J., \& Kober, H. (2011). Meditation experience is associated with differences in default mode network activity and connectivity. Proceedings of the National Academy of Sciences of the United States of America, 108, 20254-20259.

Brownsett, S. L. E., \& Wise, R. J. S. (2010). The contribution of the parietal lobes to speaking and writing. Cerebral Cortex, 20, 517-523.

Bruineberg, J., Kiverstein, J., \& Rietveld, E. (2018). The anticipating brain is not a scientist: the free-energy principle from an ecological-enactive perspective. Synthese, 195, 2417-2444.

Budwig, N. (2000). Language and the construction of self: Developmental reflections. In N. Budwig, I. C. Uzgiris, \& J. V. Wertsch (Eds.), Communication: An Arena of Development (pp. 195-214). Stamford, CT: Ablex.

Butterworth, G. (2000). An ecological perspective on the self and its development. In D. Zahavi (Ed.), Exploring the self. Philosophical and psychopathological perspectives on self-experience (pp. 19-38). Amsterdam: John Benjamins.

Campbell, J. D., Trapnell, P. D., Heine, S. J., Katz, I. M., Lavallee, L. F., \& Lehman, D. R. (1996). Self-concept clarity: Measurement, personality correlates, and cultural boundaries. Journal of Personality and Social Psychology, 70(1), 141-156.

Carruthers, G. (2008). Types of body representation and the sense of embodiment. Consciousness and Cognition, 17, 1302-1316.

Cassam, Q. (1997). Self and world. Oxford: Oxford University Press.

Chatterjee, T. (1982). The concept of sāksin. Journal of Indian Philosophy, 10(4), 339-356.

Chen, A. C., Oathes, D. J., Chang, C., Bradley, T., Zhou, Z. W., Williams, L. M , ... Etkin, A. (2013). Causal interactions between fronto-parietal central executive and default-mode networks in humans. Proceedings of the National Academy of Sciences of the United States of America, 110, 19944-19949. 
Chiong, W. (2011). The self: From philosophy to cognitive neuroscience. Neurocase: The Neural Basis of Cognition, 17(3), 190-200.

Cicogna, P., \& Bosinelli, M. (2001). Consciousness during dreams. Consciousness and Cognition, 10, 2641.

Craig, A. D. (2004). Human feelings: why are some more aware than others? Trends in Cognitive Sciences, $8,239-241$.

Craig, A. D. (2009). How do you feel - now? The anterior insula and human awareness. Nature Reviews Neuroscience, 10, 59-70.

Craig, A. D. (2010). The sentient self. Brain Structure and Function, 214, 563-577.

Craver, C. F. (2001). Role functions, mechanisms and hierarchy. Philosophy of Science, 68, 53-74.

Critchley, H. D., Wiens, S., Rotshtein, P., Ohman, A., \& Dolan, R. J. (2004). Neural systems supporting interoceptive awareness. Nature Neuroscience, 7, 189-195.

Dalai Lama, XIV. (1991). Path to Bliss. Ithaca, NY: Snow Lion.

Damasio, A. R. (1994). Descartes' error: Emotion, reason and the human brain. New York: Grosset/Putnam.

Damasio, A. R. (1999). The feeling of what happens: Body and emotion in the making of consciousness. San Diego, CA: Harcourt Brace.

Damasio, A. R. (2010). When self comes to mind. New York, NY: Pantheon Books.

Damasio, A. R., \& Carvalho, G. B. (2013). The nature of feelings: Evolutionary and neurobiological origins. Nature Reviews Neuroscience, 14(2), 143-152.

D’Argembeau, A., Collette, F., Van der Linden, M., Laureys, S., Del Fiore, G., Degueldre, C., ... Salmon, E. (2005). Self-referential reflective activity and its relationship with rest. A PET study. NeuroImage, 25, 616-624.

Davey, C. G., Pujol, J., \& Harrison, B. J. (2016). Mapping the self in the brain's default mode network. NeuroImage, 132, 390-397.

Davidson, R. J. (2010). Empirical explorations of mindfulness: conceptual and methodological conundrums. Emotion, 10, 8-11.

Deane, G. (2020). Dissolving the self: Active inference, psychedelics, and ego-dissolution. Philosophy and the Mind Sciences, 1(I), 2. https://doi.org/10.33735/phimisci.2020.I.39

Deikman, A. J. (1982). The observing self: Mysticism and psychotherapy. Boston, MA: Beacon Press.

Demiray, B., \& Bluck, S. (2011). The relation of the conceptual self to recent and distant autobiographical memories. Memory, 19(8), 975-992.

Deng, Y. Q., Li, S., \& Tang, Y. Y. (2014). The relationship between wandering mind, depression and mindfulness. Mindfulness, 5, 124-128.

Depraz, N., Varela, F., \& Vermersch, P. (Eds.). (2003). On becoming aware: A pragmatics of experiencing. Amsterdam: John Benjamins.

De Ridder, D., Van Laere, K., Dupont, P., Menovsky, T., \& Van de Heyning, P. (2007). Visualizing out-ofbody experience in the brain. New England Journal of Medicine, 357, 1829-1833.

de Vignemont, F. (2010). Body Schema and Body image - pros and cons. Neuropsychologia, 48(3), 669680.

de Vignemont F, \& Fourneret P. (2004). The sense of agency: a philosophical and empirical review of the "Who" system. Consciousness and Cognition, 13, 1-19.

Diagnostic and statistical manual of mental disorders. 5th ed. (2013). Arlington, VA: The American Psychiatric Association.

Dor-Ziderman, Y., Berkovich-Ohana, A., Glicksohn, J., \& Goldstein, A. (2013). Mindfulness-induced selflessness: a MEG neurophenomenological study. Frontiers in Human Neuroscience, 7, 582. doi:10.3389/fnhum.2013.00582

Downing, P. E., Jiang, Y., Shuman, M., \& Kanwisher, N. (2001). A cortical area selective for visual processing of the human body. Science, 293(5539), 2470-2473.

Fair, D. A., Cohen, A. L., Dosenbach, N. U., Church, J. A., Miezin, F. M., Barch, D. M., ... Schlaggar, B. L. (2008). The maturing architecture of the brain's default network. Proceedings of the National Academy of Sciences of the United States of America, 105, 4028-4032.

Farrer, C., \& Frith, C. D. (2002). Experiencing oneself vs another person as being the cause of an action: the neural correlates of the experience of agency. Neurolmage, 15, 596-603. 
Farrer, C., Franck, N., Georgieff, N., Frith, C. D., Decety, J., \& Jeannerod, M. (2003). Modulating the experience of agency: A positron emission tomography study. NeuroImage, 18(2), 324-333.

Fasching, W. (2010). 'I am of the nature of Seeing': Phenomenological reflections on the Indian notion of witness-consciousness. In M. Siderits, M. E. Thompson \& D. Zahavi (Eds.), Self, no Self?: Perspectives from analytical, phenomenological, and Indian traditions (pp. 193-216). Oxford: OUP.

Fazelpour, S., \& Thompson, E. (2015). The Kantian brain: brain dynamics from a neurophenomenological perspective. Current Opinion in Neurobiology, 31, 223-229.

Feinberg, T. E. (2012). Neuroontology, neurobiological naturalism, and consciousness: a challenge to scientific reduction and a solution. Physics of Life Reviews, 9(1), 13-34.

Fingelkurts, A. A., \& Fingelkurts, A. A. (2001). Operational architectonics of the human brain biopotential field: Towards solving the mind-brain problem. Brain and Mind, 2(3), 261-296.

Fingelkurts, A. A., \& Fingelkurts, A. A. (2008). Brain-mind operational architectonics imaging: Technical and methodological aspects. The Open Neuroimaging Journal, 2, 73-93.

Fingelkurts, A. A., \& Fingelkurts, A. A. (2011). Persistent operational synchrony within brain default-mode network and self-processing operations in healthy subjects. Brain and Cognition, 75, 79-90.

Fingelkurts, A. A., \& Fingelkurts, A. A. (2010). Short-term EEG spectral pattern as a single event in EEG phenomenology. The Open Neuroimaging Journal, 4, 130-156.

Fingelkurts, A. A., \& Fingelkurts, A. A. (2012). Mind as a nested operational architectonics of the brain. Physics of Life Reviews, 9, 49-50.

Fingelkurts, A. A, \& Fingelkurts, A. A. (2013). Dissipative many-body model and a nested operational architectonics of the brain. Physics of Life Reviews, 10, 103-105.

Fingelkurts, A. A., \& Fingelkurts, A. A. (2014). EEG oscillatory states: Universality, uniqueness and specificity across healthy-normal, altered and pathological brain conditions. PLoS ONE, 9(2), e87507. doi:10.1371/journal.pone.0087507.

Fingelkurts, A. A., \& Fingelkurts, A. A. (2015a). Operational architectonics methodology for EEG analysis: Theory and results. Neuromethods, 91, 1-59. doi: 10.1007/7657_2013_60

Fingelkurts, A. A., \& Fingelkurts, A. A. (2015b). Attentional state: From automatic detection to willful focused concentration. In G. Marchetti, G. Benedetti, \& A. Alharbi (Eds.), Attention and meaning. The attentional basis of meaning (pp. 133-150). New York: Nova Science Publishers, Inc.

Fingelkurts, A. A., \& Fingelkurts, A. A. (2017a). Three-dimensional components of selfhood in treatmentnaive patients with major depressive disorder: A resting-state qEEG imaging study. Neuropsychologia, 99, 30-36.

Fingelkurts, A. A., \& Fingelkurts, A. A. (2017b). Longitudinal dynamics of 3-dimensional components of selfhood after severe traumatic brain injury: A qEEG case study. Clinical EEG and Neuroscience, 48(5), 327-337.

Fingelkurts, A. A., \& Fingelkurts, A. A. (2018). Alterations in the Three Components of Selfhood in Persons with Post-Traumatic Stress Disorder Symptoms: A Pilot qEEG Neuroimaging Study. The Open Neuroimaging Journal, 12, 42-54.

Fingelkurts, A. A., Fingelkurts, A. A., \& Kähkönen, S. (2005). Functional connectivity in the brain -is it an elusive concept? Neuroscience and Biobehavioral Reviews, 28, 827-836.

Fingelkurts, A. A., Fingelkurts, A. A., \& Neves, C. F. H. (2010). Natural world physical, brain operational, and mind phenomenal space-time. Physics of Life Reviews, 7, 195-249.

Fingelkurts, A. A., Fingelkurts, A. A., \& Neves, C. F. H. (2013). Consciousness as a phenomenon in the operational architectonics of brain organization: Criticality and self-organization considerations. Chaos, Solitons \& Fractals, 55, 13-31.

Fingelkurts, A. A., Fingelkurts, A. A., \& Kallio-Tamminen, T. (2015). EEG-guided meditation: A personalized approach. Journal of Physiology-Paris, 109(4-6), 180-190.

Fingelkurts, A. A., Fingelkurts, A. A., \& Kallio-Tamminen, T. (2016b). Long-term meditation training induced changes in the operational synchrony of default mode network modules during a resting state. Cognitive Processing, 17(1), 27-37.

Fingelkurts, A. A., Fingelkurts, A. A., Kallio-Tamminen, T. (2016c). Trait lasting alteration of the brain default mode network in experienced meditators and the experiential selfhood. Self and Identity, 15(4), 381-393. 
Fingelkurts, A. A., Fingelkurts, A. A., Bagnato, S., Boccagni, C., \& Galardi, G. (2012). DMN operational synchrony relates to self-consciousness: evidence from patients in vegetative and minimally conscious states. The Open Neuroimaging Journal, 6, 55-68.

Fingelkurts, A. A., Fingelkurts, A. A., Bagnato, S., Boccagni, C., \& Galardi, G. (2016a). The chief role of frontal operational module of the brain default mode network in the potential recovery of consciousness from the vegetative state: A preliminary comparison of three case reports. The Open Neuroimaging Journal, 10(Suppl-1, M4), 41-51.

Fingelkurts, A. A., Fingelkurts, A. A., Neves, C. F. H., \& Kallio-Tamminen, T. K. (2019). Brain-mind operational architectonics: At the boundary between quantum physics and Eastern metaphysics. Physics of Life Reviews, 31, 122-133.

Farmer, H., \& Tsakiris, M. (2012). The bodily social self: a link between phenomenal and narrative selfhood. Review of Philosophy and Psychology, 3, 125-144.

Forman, R. K. C. (1998). What does mysticism have to teach us about consciousness? Journal of Consciousness Studies, 5(2), 185-201.

Fort, A. O. (1984). The concept of sākșin in Advaita Vedānta. Journal of Indian Philosophy, 12(3), 277-290.

Fox, K. C., Zakarauskas, P., Dixon, M., Ellamil, M., \& Thompson, E. C. (2012). Meditation experience $\begin{array}{lllll}\text { predicts introspective } & \text { accuracy. }\end{array}$ http://dx.doi.org/10.1371/journal.pone.0045370

Fox, K. C. R., Spreng, R. N., Ellamil, M., Andrews-Hanna, J. R., \& Christoff, K. (2015). The wandering brain: Meta-analysis of functional neuroimaging studies of mind-wandering and related spontaneous thought processes. NeuroImage, 111, 611-621.

Fransson, P., Skiöld, B., Horsch, S., Nordell, A., Blennow, M., Lagercrantz, H., \& Aden, U. (2007). Restingstate networks in the infant brain. Proceedings of the National Academy of Sciences of the United States of America, 104, 15531-15536.

Fransson, P., Skiöld, B., Engström, M., Hallberg, B., Mosskin, M., Aden, U., ... Blennow, M. (2009). Spontaneous brain activity in the newborn brain during natural sleep - an fMRI study in infants born at full term. Pediatric Research, 66, 301-305.

Freeman, W., \& Kozma, R. (2000). Local-global interactions and the role of mesoscopic (intermediaterange) elements in brain dynamics. Behavioral and Brain Sciences, 23(3), 401-401.

Freeman, W. J., \& Vitiello G. (2006). Nonlinear brain dynamics as macroscopic manifestation of underlying many-body field dynamics. Physics of Life Reviews, 3, 93-118.

Freeman, W. J., Kozma, R., Li, G., Quiroga, R. Q., Vitiello, G., \& Zhang, T. (2015). Advanced models of cortical dynamics in perception. Advances in Cognitive Neurodynamics, 4, 127-136.

Frewen, P., Schroeter, M. L., Riva, G., Cipresso, P., Fairfield, B., Padulo, C., ... Northoff, G. (2020). Neuroimaging the consciousness of self: Review, and conceptual-methodological framework. Neuroscience and Biobehavioral Reviews, 112, 164-212.

Friston, K. J. (1994). Functional and effective connectivity in neuroimaging: A synthesis. Human Brain Mapping, 2, 56-78.

Friston, K. J. (2011). Embodied inference: or "I think therefore I am, if I am what I think". In W. Tschacher, C. Bergomi (Eds.), The implications of embodiment (cognition and communication) (pp. 89-125). Exeter, England: Imprint Academic.

Friston, K. (2012). Prediction, perception and agency. International Journal of Psychophysiology, 83, 248252

Friston, K. (2018). Am I self-conscious? Or does self-organization entail self-consciousness? Frontiers in Psychology, 9, 579. https://doi.org/10.3389/fpsyg.2018.00579

Friston, K. J., Rosch, R., Parr, T., Price, C., \& Bowman, H. (2017). Deep temporal models and active inference. Neuroscience and Biobehavioral Reviews, 90, 486-501.

Frith, C. D. (1992). The cognitive neuroscience of schizophrenia. Hillsdale, NJ: Erlbaum.

Frith, C. D., \& Metzinger, T. (2016). What's the use of consciousness? How the stab of conscience made us really conscious. In A. K. Engel, K. J. Friston, \& D. Kragic (Eds.), The pragmatic turn: Toward actionoriented views in cognitive science (pp.193-214). Cambridge, MA: MIT Press.

Gallagher, S. (1986). Body image and body schema: A conceptual clarification. Journal of Mind and Behaviour, 7(4), 541-554.

Gallagher, S. (2000). Philosophical conceptions of the self: Implications for cognitive science. Trends in Cognitive Sciences, 4, 14-21. 
Gallagher, S. (2003a). Self-narrative in schizophrenia. In T. Kircher, \& A. David (Eds.), The self in neuroscience and psychiatry (pp. 336-357). Cambridge: Cambridge University Press.

Gallagher, S. (2003b). Phenomenology and experimental design. Journal of Consciousness Studies, 10(9$10), 85-99$.

Gallagher, S. (2005). How the body shapes the mind. Oxford: Clarendon Press.

Gallagher, S. (2013). A pattern theory of self. Frontiers in Human Neuroscience, 7, 443. doi: 10.3389 /fnhum. 2013.00443

Gallagher, H. L., \& Frith, C. D. (2003). Functional imaging of 'theory of mind'. Trends in Cognitive Science, 7, 77-83.

Gallagher, S., \& Sørensen, J. B. (2006). Experimenting with phenomenology. Consciousness and Cognition, $15,119-134$.

Gallagher, S., \& Zahavi, D. (2012). The phenomenological mind. An introduction to philosophy of mind and cognitive science (2nd Ed.). London: Routledge.

Gallagher, S., \& Zahavi, D. (2015). Phenomenological approaches to self-consciousness. In E. N. Zalta (Ed.), The Stanford encyclopedia of philosophy (Spring Edition), URL = http://plato.stanford.edu/archives/spr2015/entries/self-consciousness-phenomenological/

Gallagher, S., \& Allen, M. (2018). Active inference, enactivism and the hermeneutics of social cognition. Synthese, 195, 2627-2648.

Gallagher, S., \& Daly, A. (2018). Dynamical relations in the self-pattern. Frontiers in Psychology, 9, 664. doi: 10.3389 /fpsyg.2018.00664

Gao, W., Zhu, H., Giovanello, K. S., Smith, J. K., Shen, D., Gilmore, J. H., \& Lin, W. (2009). Evidence on the emergence of the brain's default network from 2-week-old to 2-year-old healthy pediatric subjects. Proceedings of the National Academy of Sciences of the United States of America, 106, 6790-6795.

Gardiner, J. M. (2001). Episodic memory and autonoetic consciousness: A first-person approach. Philosophical Transactions of the Royal Society of London. Series B, Biological Sciences, 356, 13511361.

Gasser. T., Verleger, R., Bacher, P., \& Sroka, L. (1988a). Development of the EEG of school age children and adolescents. I. Analysis of band power. Electroencephalography and Clinical Neurophysiology, 69, 91-99.

Giummarra, M. J., Gibson, S. J., Georgiou-Karistianis, N., \& Bradshaw, J. L. (2008). Mechanisms underlying embodiment, disembodiment and loss of embodiment. Neuroscience and Biobehavioral Reviews, 32, 143-160.

Gopnik, A., \& Slaughter, V. (1991). Young children's understanding of changes in their mental states. Child Development, 67, 98-110.

Graham, K. T., Martin-Iverson, M. T., Holmes, N. P., Jablensky, A., \& Waters, F. (2014). Deficits in agency in schizophrenia and additional deficits in body image, body schema and interna ltiming, in passivity symptoms. Frontiers in Psychiatry, 5, 126. doi:10.3389/fpsyt.2014.001

Green, C. E. (1968). Out-of-the-body experiences. Oxford: Institute of Psychophysical Research.

Greicius, M. D., Kiviniemi, V., Tervonen, O., Vainionpaa, V., Alahuhta, S., Reiss, A. L., \& Menon, V. (2008). Persistent default-mode network connectivity during light sedation. Human Brain Mapping, 29, 839-847.

Gruberger, M., Maron-Katz, A., Sharon, H., Hendler, T., \& Ben-Simon, E. (2013). The wandering mood: Psychological and neural determinants of rest-related negative affect. Frontiers in Psychology, 4, 961.

Gupta, B. (1998). The disinterested witness: A fragment of Advaita Vedānta phenomenology. Evanston: Northwestern University Press.

Gusnard, D. A. (2005). Being a self: considerations from functional imaging. Consciousness and Cognition, 14, 679-697.

Gusnard, D. A., \& Raichle, M. E. (2001). Searching for a baseline: functional imaging and the resting human brain. Nature Reviews Neuroscience, 2, 685.

Haanila, H. (2015). Some notions about the connections between consciousness and self-consciousness. Toward a Science of Consciousness 2015. Book of Abstracts, p. 154.

Haggard, P., Taylor-Clarke, M., \& Kennett, S. (2003). Tactile perception, cortical representation and the bodily self. Current Biology, 13, R170-R173.

Haken, H. (1977). Synergetics. An introduction. Berlin: Springer.

Haken, H. (2004). Synergetics. Introduction and advanced topics. Berlin: Springer. 
Harvey, P. (2012). An introduction to Buddhism: Teachings, history and practices (2nd Ed.). New York: Cambridge University Press.

Harrison, N. A., Gray, M. A., Gianaros, P. J., \& Critchley, H. D. (2010). The embodiment of emotional feelings in the brain. The Journal of Neuroscience, 30, 12878-12884.

Hashimoto, T., Tayama M., Miyazaki M., Fujii E., Harada M., Miyashi H., .. Kuroda Y. (1995). Developmental brain changes investigated with proton magnetic resonance spectroscopy. Developmental Medicine \& Child Neurology, 37, 398-405

Herbert, B. M. (2015). Psychophysiological mechanisms of "embodiment": The relevance of "interoception" as a basis of the embodied mind. Toward a Science of Consciousness 2015. Book of Abstracts, p. 109.

Hirsh, J. B., Mar, R. A., \& Peterson, J. B. (2013). Personal narratives as the highest level of cognitive integration. The Behavioral and Brain Sciences, 36, 216-217.

Hohwy, J. (2007). The sense of self in the phenomenology of agency and perception. Psyche (Stuttg), 13, 120. http://psyche.cs.monash.edu.au/

Hohwy, J. (2010). The hypothesis testing brain: some philosophical applications. In ASCS09: Proceedings of the 9th Conference of the Australasian Society for Cognitive Science, Sydney, Australia, pp. 135-144.

Hohwy, J. (2013). The predictive mind. Oxford: Oxford University Press.

Hohwy, J. (2016). The self-evidencing brain. Noûs, 50(2), 259-285.

Huang, Z., Dai, R., Wu, X., Yang Z., Liu, D., Hu, J., ... Northoff, G. (2014). The self and its resting state in consciousness: An investigation of the vegetative state. Human Brain Mapping, 35, 1997-2008.

Hurley, S. L. (1998). Consciousness in action. Cambridge, MA: Harvard University Press.

Ionta, S., Heydrich, L., Lenggenhager, B., Mouthon, M., Fornari, E., Chapuis, D., ... Blanke, O. (2011). Multisensory mechanisms in temporo-parietal cortex support self-location and first-person perspective. Neuron, 70, 363-374.

Jack, A. I., \& Roepstorff, A. (2002). Introspection and cognitive brain mapping: from stimulus-response to script-report. Trends in Cognitive Sciences, 6, 333-339.

James, W. (1884), What is an emotion? Mind, 9, 188-205.

James, W. (1890). The principles of psychology. New York: Henry Holt and Company.

Jann, K., Dierks, T., Boesch, C., Kottlowa, M., Strik, W., \& Koenig, T. (2009). BOLD correlates of EEG alpha phase-locking and the fMRI default mode network. NeuroImage, 45, 903-916.

Jeannerod, M. (2007). From my self to other selves: A revised framework for the self/other differentiation.

In P. Haggard, Y. Rossetti, \& M. Kawato (Eds.), Sensorimotor foundations of higher cognition: Attention and performance XXII (pp. 233-248). Oxford: Oxford University Press.

Josipovic, Z. (2014). Neural correlates of nondual awareness in meditation. Annals of the New York Academy of Sciences, 1307, 9-18.

Josipovic, Z. (2019). Nondual awareness: Consciousness-as-such as non-representational reflexivity. Progress in Brain Research, 244, 273-298.

Kerr, C. E., Josyula, K., \& Littenberg, R. (2011). Developing an observing attitude: an analysis of meditation diaries in an MBSR clinical trial. Clinical Psychology \& Psychotherapy, 18, 80-93.

Kim, H. (2012). A dual-subsystem model of the brain's default network: self-referential processing, memory retrieval processes, and autobiographical memory retrieval. NeuroImage, 61, 966-977.

Kinsbourne, M. (1995) Awareness of one's own body: An attentional theory of its nature, development, and brain basis. In J. L. Bermúdez, A. J. Marcel, \& N. Eilan (Eds.), The body and the self (pp. 205-223). Cambridge, MA: MIT Press.

Kirmayer, L. J, \& Crafa, D. (2014). What kind of science for psychiatry? Frontiers in Human Neuroscience, 8, 435. doi:10.3389/fnhum.2014.00435

Kjellgren, A., Lyden, F., \& Norlander, T. (2008). Sensory isolation in flotation tanks: Altered states of consciousness and effects on well-being. The Qualitative Report, 13(4), 636-656.

Klein, S. B. (2010). The self: As a construct in psychology and neuropsychological evidence for its multiplicity. Wiley Interdisciplinary Reviews Cognitive Science, 1, 172-183.

Klein, S. B. (2016). Autonoetic consciousness: Reconsidering the role of episodic memory in future-oriented self-projection. Quarterly Journal of Experimental Psychology, 69(2), 381-401.

Klein, S. B, \& Gangi, C. E. (2010). The multiplicity of self: Neuropsychological evidence and its implications for the self as a construct in psychological research. Annals of the New York Academy of Sciences, 1191, 1-15. 
Klimesch, W., Sauseng, P., \& Hanslmayr, S. (2007). EEG alpha oscillations: The inhibition-timing hypothesis. Brain Research Reviews, 53, 63-88.

Knyazev, G. G., Savostyanov, A. N., Volf, N. V., Liou, M., \& Bocharov, A. V. (2012). EEG correlates of spontaneous self-referential thoughts: A cross-cultural study. International Journal of Psychophysiology, 86, 173-181.

Knyazev, G. G., Slobodskoj-Plusnin, J. Y., Bocharov, A. V., \& Pylkova, L. V. (2011). The default mode network and EEG alpha oscillations: An independent component analysis. Brain Research, 1402, 6779.

Koessler, L., Maillard, L., Benhadid, A., Vignal, J. P., Felblinger, J., Vespignani, H., \& Braun, M. (2009). Automated cortical projection of EEG sensors: anatomical correlation via the international 10-10 system. NeuroImage, 46, 64-72.

Konjedi, S, Maleeh R. A closer look at the relationship between the default network, mind wandering, negative mood, and depression. Cogn Affect Behav Neurosci (2017) 17:697-711

Kozma, R.., \& Freeman, W. J. (2009). The KIV model of intentional dynamics and decision making. Neural Networks, 22(3), 277-285.

Kullberg-Turtiainen, M., Vuorela, K., Huttula, L., Turtiainen, P., \& Koskinen, S. (2019). Individualized goal directed dance rehabilitation in chronic state of severe traumatic brain injury: A case study. Heliyon. 5(2), e01184. doi:10.1016/j.heliyon.2019.e01184

Kwan, V. S. Y., Barrios, V., Ganis, G., Gorman, J., Lange, C., Kumar, M., ... Keenan, J. P. (2007). Assessing the neural correlates of self-enhancement bias: a transcranial magnetic stimulation study. Experimental Brain Research, 182(3), 379-385.

Laufs, H., Kleinschmidt, A., Beyerle, A., Eger, E., Salek-Haddadi, A., Preibisch, C., \& Krakow, K. (2003). EEG-correlated fMRI of human alpha activity. NeuroImage, 19, 1463-1476.

Laureys, S. (2005). The neural correlate of (un)awareness: lessons from the vegetative state. Trends in Cognitive Sciences, 9, 556-559.

Leech, R., Kamourieh, S., Beckmann, C.F., \& Sharp, D.J. (2011). Fractionating the default mode network: distinct contributions of the ventral and dorsal posterior cingulate cortex to cognitive control. The Journal of Neuroscience, 31, 3217-3224.

Legrand, D. (2006). The bodily self: The sensori-motor roots of pre-reflective self-consciousness. Phenomenology and the Cognitive Sciences, 5, 89-118.

Legrand, D. (2007). Pre-reflective self-as-subject from experiential and empirical perspectives. Consciousness and Cognition, 16, 583-599.

Legrand, D., \& Ruby, P. (2009). What is self-specific? Theoretical investigation and critical review of neuroimaging results. Psychological Review, 116, 252-282.

Lenggenhager, B., Tadi, T., Metzinger, T., \& Blanke, O. (2007). Video ergo sum: Manipulating bodily selfconsciousness. Science, 317, 1096-1099.

Letheby, C. (2020). Being for no-one: Psychedelic experience and minimal subjectivity. Philosophy and the Mind Sciences, 1(I), 5. https://doi.org/10.33735/phimisci.2020.I.47

Levenson, R. W. (2003). Blood, sweat, and fears: The autonomic architecture of emotion. Annals of the New York Academy of Sciences, 1000, 348-366.

Limanowski, J., \& Blankenburg, F. (2013). Minimal self-models and the free energy principle. Frontiers in Human Neuroscience, 7, 547. doi:10.3389/fnhum.2013.00547

Livanov, M. N. (1977). Spatial organization of cerebral processes. New York: Wiley.

Longe, O., Maratos, F. A., Gilbert, P., Evans, G., Volker, F., Rockliff, H., \& Rippon, G. (2010). Having a word with yourself: neural correlates of self-criticism and self-reassurance. NeuroImage, 49, 1849-1856.

Lou, H.C., Luber, B., Crupain, M., Keenan, J.P., Nowak, M., Kjaer, T.W., ... Lisanby, S.H. (2004). Parietal cortex and representation of the mental Self. Proceedings of the National Academy of Sciences of the United States of America, 101, 6827-6832.

Lou, H. C., Luber, B., Stanford, A., \& Lisanby, S. H. (2010). Self-specific processing in the default network: a single-pulse TMS study. Experimental Brain Research, 207, 27-38.

Luber, B., Lou, H. C., Keenan, J. P., \& Lisanby, S. H. (2012). Self-enhancement processing in the default network: A single-pulse TMS study. Experimental Brain Research, 223, 177-187.

Lutz, A., \& Thompson, E. (2003). Neurophenomenology. Journal of Consciousness Studies, 10, 31-52. 
Lutz, A., Dunne, J., \& Davidson, R. (2007). Meditation and the neuroscience of consciousness: An introduction. In P. Zelazo, M. Moscovitch, \& E. Thompson (Eds.), The Cambridge handbook of consciousness (pp. 499-551). Cambridge: Cambridge University Press.

Lutz, A., Slagter, H. A., Dunne, J. D., \& Davidson, R. J. (2008). Attention regulation and monitoring in meditation. Trends in Cognitive Sciences, 12, 163-169.

Mantini, D., Perrucci, M. G., Del Gratta, C., Romani, G. L., \& Corbetta, M. (2007). Electrophysiological signatures of resting state networks in the human brain. Proceedings of the National Academy of Sciences of the United States of America, 104, 13170-13175.

Mantini, D., Della Penna, S., Marzetti, L., de Pasquale, F., Pizzella, V., Corbetta, M., \& Romani, G. L. (2011). A signal-processing pipeline for magnetoencephalography resting-state networks. Brain Connectivity, 1, 49-59.

Mar, R. A. (2004). The neuropsychology of narrative: story comprehension, story production and their interrelation. Neuropsychologia, 42, 1414-1434.

Marino, M., Arcara, G., Porcaro, C., \& Mantini, D. (2019). Hemodynamic correlates of electrophysiological activity in the default mode network. Frontiers in Neuroscience, 13, 1060. doi:10.3389/fnins.2019.01060

Matousek, M., \& Petersen, I. (1973). Frequency analysis of the EEG in normal children and adolescents. In P. Kellaway, \& I. Petersen (Eds.), Automation of clinical electroencephalography (pp.75-102). New York: Raven Press.

McNally, R. J. (2003). Remembering trauma. Cambridge, MA: Belknap Press/Harvard University Press.

Merleau-Ponty, M. (1962). Phenomenology of perception (C. Smith, Trans.). London: Routledge and Kegan Paul (original work published 1945).

Metzinger, T. (2003). Phenomenal transparency and cognitive self-reference. Phenomenology and the Cognitive Science, 2, 353-393.

Metzinger, T. (2004). Being no one: The self-model theory of subjectivity. Cambridge, MA: MIT Press.

Metzinger, T. (2008). Empirical perspectives from the self-model theory of subjectivity: A brief summary with examples. In R. Banerjee, \& B. K. Chakrabarti (Eds.), Progress in brain research (pp. 215-245). Elsevier B.V.

Metzinger, T. (2013). Why are dreams interesting for philosophers? The example of minimal phenomenal self-hood, plus an agenda for future research. Frontiers in Psychology, 4, 746. doi: 10.3389/fpsyg.2013.00746

Metzinger, T. (2020). Minimal phenomenal experience: Meditation, tonic alertness, and the phenomenology of "pure" consciousness. Philosophy and the Mind Sciences, 1(I), 7. https://doi.org/10.33735/phimisci.2020.I.46

Miall, R. C., \& Robertson, E. M. (2006). Functional imaging: is the resting brain resting? Current Biology, 16(23), R998-R1000.

Millière, R. (2017). Looking for the self: Phenomenology, neurophysiology and philosophical significance of drug-induced ego dissolution. Frontiers in Human Neuroscience, 11(245), https://doi.org/10.3389/fnhum.2017.00245

Millière, R. (2020). The varieties of selflessness. Philosophy and the Mind Sciences, 1(I), 8. https://doi.org/10.33735/phimisci.2020.I.48

Millière, R., \& Metzinger, T. (2020). Radical disruptions of self-consciousness: Editorial introduction. Philosophy and the Mind Sciences, 1(I), 1. https://doi.org/10.33735/phimisci.2020.I.50

Mišić, B., Betzel, R. F., de Reus, M. A., van den Heuvel, M. P., Berman, M. G., McIntosh, A. R., \& Sporns, O. (2016). Network-level structure-function relationships in human neocortex. Cerebral Cortex, 26, 3285-3296.

Molnar-Szakacs, I., \& Uddin, L. Q. (2013). Self-processing and the default mode network: interactions with the mirror neuron system. Frontiers in Human Neuroscience, 7, 571. doi: 10.3389/fnhum.2013.00571

Moran, J. M., Kelley, W. M., \& Heatherton, T. F. (2013). What can the organization of the brain's default mode network tell us about self-knowledge? Frontiers in Human Neuroscience, 7, 391.

Moriguchi, Y., Ohnishi, T., Lane, R. D., Maeda, M., Mori, T., Nemoto, K., ... Komaki, G. (2006). Impaired self-awareness and theory of mind: an fMRI study of mentalizing in alexithymia. NeuroImage, 32, $1472-1482$.

Morin, A. (2009). Self-awareness deficits following loss of inner speech: Dr. Jill Bolte Taylor's case study. Consciousness and Cognition, 18(2), 524-529. 
Morin, A. (2011). Self-awareness Part 1: Definition, measures, effects, functions, and antecedents. Social and Personality Psychology Compass, 5(10), 807-823.

Moseley, P., Fernyhough, C., \& Ellison, A. (2013). Auditory verbal hallucinations as atypical inner speech monitoring, and the potential of neurostimulation as a treatment option. Neuroscience and Biobehavioral Reviews, 37, 2794-2805.

Múnera, C. P., Lomlomdjian, C., Gori, B., Terpiluk, V., Medel, N., Solís, P., \& Kochen, S. (2014). Episodic and semantic autobiographical memory in temporal lobe epilepsy. Epilepsy Research and Treatment, 2014, 157452. doi:10.1155/2014/157452.

Musholt, K. (2013). A philosophical perspective on the relation between cortical midline structures and the self. Frontiers in Human Neuroscience, 7, 536. doi: 10.3389/fnhum.2013.00536

Musholt, K. (2015). Thinking about oneself: From nonconceptual content to the concept of a Self. Cambridge: MIT Press.

Nash, J. D., Newberg, A., \& Awasthi, B. (2013). Toward a unifying taxonomy and definition for meditation. Frontiers in Psychology, 4, 806. doi: 10.3389/fpsyg.2013.00806

Neisser, U. (1988). Five kinds of self-knowledge. Philosophical Psychology, 1, 35-59.

Newberg, A, \& Iversen, J. (2003). The neural basis of the complex mental task of meditation: neurotransmitter and neurochemical considerations. Medical Hypotheses, 61, 282-291.

Newberg, A., Alavi, A., Baime, M., Pourdehnad, M., Santanna, J., \& d'Aquili, E. G. (2001). The measurement of regional cerebral blood flow during the complex cognitive task of meditation: a preliminary SPECT study. Psychiatry Research, 106, 113-122.

Nimchinsky, E. A., Gilissen, E., Allman, J. M., Perl, D. P., Erwin, J. M., \& Hof, P. R. (1999). A neuronal morphologic type unique to humans and great apes. Proceedings of the National Academy of Sciences of the United States of America, 96, 5268-5273.

Noë, A. (2005). Action in perception. Cambridge, MA: The MIT Press.

Nolen-Hoeksema, S., Wisco, B. E., \& Lyubomirsky, S. (2008). Rethinking rumination. Perspectives on Psychological Science, 3, 400-424.

Norman, G. (2010). Likert scales, levels of measurement and the "laws" of statistics. Advances in Health Science Education, 15(5), 625-632.

Northoff, G. (2007). Psychopathology and pathophysiology of the self in depression - neuropsychiatric hypothesis. Journal of Affective Disorders, 104, 1-14.

Northoff, G. (2014a). Unlocking the brain. Vol II, Consciousness. Oxford: Oxford University Press.

Northoff, G. (2014b). Minding the brain. A Guide to philosophy and neuroscience. London: Palgrave MacMillan.

Northoff, G. (2016). Is the self a higher-order or fundamental function of the brain? The 'basis model of selfspecificity' and its encoding by the brain's spontaneous activity. Cognitive Neuroscience, 7, 203-222.

Northoff, G., \& Bermpohl, F. (2004). Cortical midline structures and the self. Trends in Cognitive Sciences, $8(3), 102-107$.

Northoff, G., Qin, P., \& Feinberg, T. E. (2011). Brain imaging of the self - Conceptual, anatomical and methodological issues. Consciousness and Cognition, 20, 52-63.

Northoff, G., Heinzel, A., de Greck, M., Bermpohl, F., Dobrowolny, H., \& Panksepp, J. (2006). Selfreferential processing in our brain. A meta-analysis of imaging studies on the self. NeuroImage, 31, 440-457.

Nour, M. M., \& Carhart-Harris, R. L. (2017). Psychedelics and the science of self-experience. The British Journal of Psychiatry, 210, 177-179.

Nummenmaa, L., Glerean, E., Hari, R., \& Hietanen, J. K. (2014). Bodily maps of emotions. Proceedings of the National Academy of Sciences of the United States of America, 111(2), 646-651.

Palva, S., \& Palva, J. M. (2007). New vistas for alpha-frequency band oscillations. Trends in Neurosciences, $30,150-158$.

Panksepp, J. (2005). On the embodied neural nature of the core emotional affects. Journal of Consciousness Studies, 5, 158-184.

Panksepp, J., \& Northoff, G. (2009). The trans-species core SELF: The emergence of active cultural and neuro-ecological agents through self-related processing within subcortical-cortical midline networks. Consciousness and Cognition, 18, 193-215. 
Park, H. D., \& Tallon-Baudry, C. (2014). The neural subjective frame: from bodily signals to perceptual consciousness. Philosophical Transactions of the Royal Society of London. Series B, Biological Sciences, 369, 20130208. doi:10.1098/rstb.2013.0208

Parnas, J., \& Handest, P. (2003). Phenomenology of anomalous self-experience in early schizophrenia. Comprehensive Psychiatry, 44(2), 121-134.

Paulus, M. P., \& Stein, M. B. (2010). Interoception in anxiety and depression. Brain Structure and Function, 214(5-6), 451-463.

Perlovsky, L. (2011). Language and cognition interaction neural mechanisms. Computational Intelligence and Neuroscience, 2011, 454587. doi:10.1155/2011/454587

Perneger, T. V. (1998). What's wrong with Bonferroni adjustments. British Medical Journal, 316, 12361238.

Piolino, P., Desgranges, B., \& Eustache, F. (2009). Episodic autobiographical memories over the course of time: Cognitive, neuropsychological and neuroimaging findings. Neuropsychologia, 47, 2314-2329.

Pitrona, V., \& de Vignemonta, F. (2017). Beyond differences between the body schema and the body image: insights from body hallucinations. Consciousness and Cognition, 53, 115-121.

Polito, V., Barnier, A. J., \& Woody, E. Z. (2013) Developing the Sense of Agency Rating Scale (SOARS): An empirical measure of agency disruption in hypnosis. Consciousness and Cognition, 22, 684-696.

Pollan, M. (2018). How to change your mind: What the new science of psychedelics teaches us about consciousness, dying, addiction, depression, and transcendence. New York: Penguin Press.

Pope, K. S., \& Singer, J. L. (Eds.) (1978). The stream of consciousness. New York: Plenum.

Povinelli, D., Landau, K., \& Perilloux, H. (1996). Self-recognition in young children using delayed versus live feedback: Evidence of a developmental asynchrony. Child Development, 67, 1540-1554.

Praetorius, N. (2009). The phenomenological underpinning of the notion of a minimal core self: A psychological perspective. Consciousness and Cognition, 18(1), 325-338.

Raichle, M. E., MacLeod, A. M., Snyder, A. Z., Powers, W. J., Gusnard, D. A., \& Shulman, G. L. (2001). A default mode of brain function. Proceedings of the National Academy of Sciences of the United States of America, 98, 676-682.

Revonsuo, A. (2006). Inner presence: Consciousness as a biological phenomenon. Cambridge, MA: MIT Press.

Rimes, K. A., \& Watkins, E. (2005). The effects of self-focused rumination on global negative selfjudgements in depression. Behaviour Research and Therapy, 43, 1673-1681.

Rothman, K. J. (1990). No adjustments are needed for multiple comparisons. Epidemiology, 1, 43-46.

Schilbach, L., Eickhoff, S. B., Rotarska-Jagiela, A., Fink, G. R., \& Vogeley, K. (2008). Minds at rest? Social cognition as the default mode of cognizing and its putative relationship to the "default system" of the brain. Consciousness and Cognition, 17, 457-467.

Schulz, K. F., \& Grimes, D. A. (2005). Multiplicity in randomised trials I: endpoints and treatments. Lancet, $365,1591-1595$.

Schwenkler, J. (2014). Vision, self-location, and the phenomenology of the "point of view". Noûs, 48(1), $137-155$.

Seeley, W. W., Carlin, D. A., Allman, J. M., Macedo, M. N., Bush, C., Miller, B. L., Dearmond, S. J. (2006). Early frontotemporal dementia targets neurons unique to apes and humans. Annals of Neurology, 60(6), 660-667.

Sestieri, C., Corbetta, M., Romani, G. L., \& Shulman, G. L. (2011). Episodic memory retrieval, parietal cortex, and the default mode network: functional and topographic analyses. The Journal of Neuroscience, 31, 4407-4420.

Seth, A. K. (2013). Interoceptive inference, emotion, and the embodied self. Trends in Cognitive Sciences, $17,565-573$.

Seth, A. K., \& Critchley, H. D. (2013). Extending predictive processing to the body: Emotion as interoceptive inference. The Behavioral and Brain Sciences, 36, 227-228.

Seth, A. K., Suzuki, K., \& Critchley, H. D. (2012). An interoceptive predictive coding model of conscious presence. Frontiers in Psychology, 2, 395. doi: 10.3389/fpsyg.2011.00395

Shear, J. (2007). Eastern methods for investigating mind and consciousness. In S. Schneider, \& M. Velmans (Eds.), The Blackwell companion to consciousness (pp. 697-710). Malden, MA: John Wiley \& Sons.

Shotter, J. (1997). The social construction of our "inner" lives. Journal of Constructivist Psychology, 10, $7-$ 24. 
Sikka, P., Valli, K., Virta, T., \& Revonsuo, A. (2014). I know how you felt last night, or do I? Self- and external ratings of emotions in REM sleep dreams. Consciousness and Cognition, 25, 51-66.

Snodgrass, J. G., \& Thompson, R. L. (1997). The self across psychology: Self-recognition, self-awareness, and the self-concept. New York: New York Academy of Sciences.

Spreng, R.N., \& Grady, C.L. (2010). Patterns of brain activity supporting autobiographical memory, prospection, and theory-of-mind and their relationship to the default mode network. Journal of Cognitive Neuroscience, 22, 1112-1123.

Strawson, G. (1997). The self. Journal of Consciousness Studies, 4, 405-428.

Strawson, G. (1999). The self and the SESMET. Journal of Consciousness Studies, 6, 99-135.

Sugimori, E., Asai, T., \& Tanno, Y. (2011). Sense of agency over speech and proneness to auditory hallucinations: the reality-monitoring paradigm. Quarterly Journal of Experimental Psychology, 64, $169-185$.

Taylor, J. B. (2006). My stroke of insight: A brain scientist's personal journey. New York: Viking.

Thompson, E. (2015). Dreamless sleep, the embodied mind, and consciousness. In T. K. Metzinger \& J. M. Windt (Eds.), Open MIND, Chapter 37(T). Frankfurt am Main: MIND Group. https://doi.org/10.15502/9783958570351

Thompson, E., \& Stapleton, M. (2009). Making sense of sense-making: reflections on enactive and extended mind theories. Topoi, 28, 23-30.

Thomason, M. E., Chang, C. E., Glover, G. H., Gabrieli, J. D., Greicius, M. D., \& Gotlib, I. H. (2008). Default-mode function and task-induced deactivation have overlapping brain substrates in children. NeuroImage, 41, 1493-1503.

Tomasello, M., \& Rakoczy, H. (2003). What makes human cognition unique? From individual to shared to collective intentionality. Mind \& Language, 18, 121-147.

Tops, M., Boksem, M. A. S., Quirin, M. I., Jzerman, H., \& Koole, S. L. (2014). Internally directed cognition and mindfulness: An integrative perspective derived from predictive and reactive control systems theory. Frontiers in Psychology, 5, 429. doi: 10.3389/fpsyg.2014.00429

Trapnell, P. D., \& Campgell, J. D. (1999). Private self-consciousness and the Five-Factor model of personality: Distinguishing rumination from reflection. Journal of Personality and Social Psychology, 76(2), 284-304.

Travis, F., \& Pearson, C. (2000). Pure consciousness: distinct phenomenological and physiological correlates of "consciousness itself." The International Journal of Neuroscience, 100, 77-89.

Trehub, A. (2007). Space, self, and the theater of consciousness. Consciousness and Cognition, 16, 310-330.

Tsakiris, M. (2010). My body in the brain: a neurocognitive model of body-ownership. Neuropsychologia, $48,703-712$.

Tsakiris, M., Schütz-Bosbach, S., \& Gallagher, S. (2007). On agency and body-ownership: phenomenological and neurocognitive reflections. Consciousness and Cognition, 16, 645-660.

Tsakiris, M., Costantini, M., \& Haggard, P. (2008). The role of the right temporo-parietal junction in maintaining a coherent sense of one's body. Neuropsychologia, 46, 3014-3018.

Tsakiris, M., Tajadura-Jiménez, A., \& Costantini, M. (2011). Just a heartbeat away from one's body: Interoceptive sensitivity predicts malleability of body-representations. Proceedings of the Royal Society of London. Series B, Biological Sciences, 278, 2470-2476.

Tulving, E. (2002). Episodic memory: From mind to brain. Annual Review of Psychology, 53, 1-25.

Tulving, E., Schacter, D. L., McLachlan, D. R., \& Moscovitch, M. (1988). Priming of semantic autobiographical knowledge: A case study of retrograde amnesia. Brain and Cognition, 8, 2-20.

Uddin, L. Q., Kelly, A. M., Biswal, B. B., Castellanos, F. X., \& Milham, M. P. (2009). Functional connectivity of default mode network components: correlation, anticorrelation, and causality. Human Brain Mapping, 30, 625-637.

Vago, D. R., \& Silbersweig, D. A. (2012). Self-awareness, self-regulation, and self-transcendence (S-ART): a framework for understanding the neurobiological mechanisms of mindfulness. Frontiers in Human Neuroscience, 6, 296. doi:10.3389/fnhum.2012.00296

van der Kolk, B A. (1994). The body keeps the score: Memory and the evolving psychobiology of posttraumatic stress. Harvard Review of Psychiatry, 1(5), 253-265.

van der Kolk, B. A., \& Fisler, R. (1995). Dissociation and the fragmentary nature of traumatic memories: Overview and exploratory study. Retrieved from David Baldwin's Trauma Pages: http://www.traumapages.com/a/vanderk2.php 
Vanhaudenhuyse, A., Noirhomme, Q., Tshibanda, L. J., Bruno, M. A., Boveroux, P., Schnakers, C., ... Boly, M. (2010). Default network connectivity reflects the level of consciousness in non-communicative brain-damaged patients. Brain, 133, 161-171.

Varela, F. J. (1996). Neurophenomenology. A methodological remedy for the hard problem. Journal of Consciousness Studies, 4, 330-349.

Varela, F., Thompson, E., \& Rosch, E. (1994). The embodied mind. Cambridge, MA: MIT Press.

Velmans, M. (2014). Conscious agency and the preconscious/unconscious Self. In S. Menon, A. Sinha, \& B.V. Sreekantan (Eds.), Interdisciplinary perspectives on consciousness and the self (pp. 11-25). New Delhi: Springer.

Vigário, R. N. (1997). Extraction of ocular artefacts from EEG using independent component analysis. Electroencephalography and Clinical Neurophysiology, 103, 395-404.

Vogeley, K., \& Fink, G. R. (2003). Neural correlates of the first-person perspective. Trends in Cognitive Sciences, 7, 38-42.

Vogeley, K., \& Gallagher, S. (2011). The self in the brain. In S. Gallagher (Ed.), The Oxford handbook of the Self (pp. 111-136). Oxford: Oxford University Press.

von Economo, C. (1926). Eine neue art spezialzellen des lobus cinguli und lobus insulae. Zeitschrift für die gesamte Neurologie und Psychiatrie, 100, 706-712.

von Economo, C., \& Koskinas, G. N. (1925). Die cytoarchitektonik der hirnrinde des erwachsenen menschen. Berlin: Springer.

Vvedensky, N. E. (1906). Excitation and inhibition in the reflex apparatus during strychnine poisoning. Leningrad: Leningrad University Publishing House.

Wahbeh, H., Sagher, A., Back, W., Pundhir, P., \& Travis, F. (2018). A systematic review of transcendent states across meditation and contemplative traditions. Explore, 14(1), 19-35.

Welsh, T. (2006). Do neonates display innate self-awareness? Why neonatal imitation fails to provide sufficient ground for innate self- and other-awareness. Philosophical Psychology, 19, 221-238.

Whitfield-Gabrieli, S., Thermenos, H. W., Milanovic, S., Tsuang, M. T., Faraone, S. V., McCarley, R. W., ... Seidman, L. J. (2009). Hyperactivity and hyperconnectivity of the default network in schizophrenia and in first-degree relatives of persons with schizophrenia. Proceedings of the National Academy of Sciences of the United States of America, 106, 1279-1284.

Windt, J. M. (2010). The immersive spatiotemporal hallucination model of dreaming. Phenomenology and the Cognitive Sciences, 9(2), 295-316.

Windt, J. M. (2013). Reporting dream experience: Why (not) to be skeptical about dream reports. Frontiers in Human Neuroscience, 7, 708. 10.3389/fnhum.2013.00708

Windt, J. M. (2014). Dreaming: A conceptual framework for philosophy of mind and empirical research. Cambridge: MIT Press.

Windt, J. M. (2015). Just in time-dreamless sleep experience as pure subjective temporality - A commentary on Evan Thompson. In T. Metzinger, \& J. M. Windt (Eds), Open MIND, Chapter 37(C). Frankfurt am Main: MIND Group. doi: 10.15502/9783958571174

Winget, C., \& Kramer, M. (1979). Dimensions of dreams. Gainesville, FL: University Press of Florida.

Wittmann, M. (2015). Modulations of the experience of self and time. Consciousness and Cognition, 38, $172-181$.

Yakovlev, P. I., \& Lecours, A. R. (1967). The myelogenetic cycles of regional maturation of the brain. In A. Minkowski (Ed.), Regional development of the brain in early life (pp. 3-70). Oxford (UK): Blackwell Scientific.

Yufik, Y. M. (2013). Understanding, consciousness and thermodynamics of cognition. Chaos, Solitons \& Fractals, 55, 44-59.

Zahavi, D. (1999). Self-awareness and alterity: A phenomenological investigation. Evanston: Northwestern Univ Press.

Zahavi, D. (2002). First-person thoughts and embodied self-awareness: Some reflections on the relation between recent analytic philosophy and phenomenology. Phenomenology and the Cognitive Sciences, 1 , 7-26.

Zahavi, D. (2006). Subjectivity and selfhood. Cambridge, MA: The MIT Press.

Zahavi D. (2014). Self and other: Exploring subjectivity, empathy, and shame. Oxford: Oxford University Press. 
Zahavi, D., \& Roepstorff, A. (2011). Faces and ascriptions: Mapping measures of the self. Consciousness and Cognition, 20, 141-148.

Zepinic, V. (2011). Understanding and treating complex trauma. London: Xlibris. 